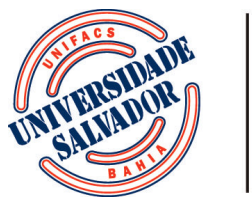

UNIVERSIDADE SALVADOR PROGRAMA DE PÓS-GRADUAÇÃO EM SISTEMAS E COMPUTAÇÃ̃O MESTRADO EM SISTEMAS E COMPUTAÇÃO

GABRIELE DA CRUZ RIBEIRO

\title{
ARCABOUÇO DE COMUNICAÇÃO \\ PUBLISH/SUBSCRIBE PARA A COLETA DE DADOS DE APLICAÇÕES MÉDICAS
}


GABRIELE DA CRUZ RIBEIRO

\section{ARCABOUÇO DE COMUNICAÇÃO PUBLISH/SUBSCRIBE PARA A COLETA DE DADOS DE APLICAÇÕES MÉDICAS}

Dissertação apresentada ao Programa de Pós-Graduação em Sistemas e Computação da Universidade Salvador, como requisito para obtenção do grau de Mestre em Sistemas e Computação.

Orientador:

Prof. Dr. Joberto S. B. Martins, PhD. em Ciência da Computação.

Salvador

2020 
RIBEIRO, Gabriele. Arcabouço de Comunicação Publish/Subscribe para a Coleta de Dados de Aplicações Médicas. 2020. (Dissertação (Mestrado)). Programa de Pós-Graduação em Sistemas e Computação. Universidade Salvador, Salvador, 2020.

\section{RESUMO}

As aplicações médicas utilizam cada vez mais os recursos da computação como o uso sistemático de sensores da Internet das Coisas (IoT) e das estruturas e paradigmas de comunicação das redes de computadores. Uma aplicação no estilo e-Health necessita de um conjunto básico de elementos tais como os sensores, um arcabouço de comunicação e uma estrutura de rede adaptados aos requisitos específicos da aplicação. Esse trabalho amplia e desenvolve um arcabouço de comunicação baseado no paradigma Publish/Subscribe visando o desenvolvimento do PSIoT-Health com um foco nas aplicações médicas que coletam dados produzidos de forma distribuída. O PSIoT-Health adapta o modelo Pub/Sub às especificidades das aplicações médicas e propõe uma solução de coleta e distribuição de dados entre produtores e consumidores de dados médicos num ambiente distribuído, típico de uma cidade inteligente.

Palavras-chaves: Aplicações Médicas, Comunicação de Dados, Internet das Coisas, Publish/ Subscribe, Cidades Inteligentes, PSIoT. 
RIBEIRO, Gabriele. Arcabouço de Comunicação Publish/Subscribe para a Coleta de Dados de Aplicações Médicas. 2020. (Dissertation). Post-Graduation Program in Computer Systems. Salvador University (UNIFACS), Salvador, Brazil, 2020.

\begin{abstract}
Medical applications are increasingly using computing resources such as IoT sensors and network communications paradigms. An e-Health application requires a basic set of elements such as sensors, a communication framework, and a network structure adapted to the application's specific requirements. This work expands and develops a framework based on the Publish / Subscribe paradigm to develop PSIoT-Health. The PSIoT-Health framework focuses on medical applications that collect data produced in a distributed manner. The PSIoT-Health adapts the Pub/Sub model to the requirements of medical applications and proposes a solution for the production and consumption of data between producers and consumers of medical data in a distributed environment such as the one existing in a smart city.
\end{abstract}

Palavras-chaves: Framework, E-Health Application, Data Communications, Internet of Things, Publish/ Subscribe, Smart City, PSIoT. 


\section{AGRADECIMENTOS}

Primeiramente agradeço ao Dono da vida e de tudo o que há nela, Jesus. Por ter aberto a porta, caminhado comigo ao longo dessa trajetória nada fácil e tranquilizado meu coração em todos os momentos de incertezas. Sou autora desse trabalho porque Jesus está de posse da caneta que está escrevendo a minha história.

Agradeço ao meu orientador, Prof. Dr. Joberto S. B. Martins por ter sido tão presente e ativo em todo o processo de construção desse trabalho, por ter me guiado com maestria ao longo dessa jornada. Me senti muito abençoada por ser orientada por um profissional tão competente, com uma carreira que tanto admiro e me inspiro.

Agradeço a minha mãe, por ter sido forte e corajosa, por ter escolhido me criar e educar diante de todas as dificuldades que uma mãe solo pode passar. Agradeço por ter sido o meu maior exemplo de garra e determinação, por ser a figura em que me espelho ao lutar pelos meus sonhos.

Agradeço a minha melhor amiga e irmã de coração, Luana, por ter sido a materialização do conceito de amizade em todos esses anos de parceria forte e a minha irmã Catiele por sempre está apostos para me dar força.

Agradeço ao meu sempre grande mestre Ridis Ribeiro, por ter sido um verdadeiro mentor ao longo desse longo caminho.

Agradeço ao meu companheiro Caio Vinícius pela compreensão e apoio.

Agradeço ao meu líder Alessandro Seixas pela solidariedade durante o processo de finalização deste trabalho e por fim, agradeço a todos que torceram por mim.

Deus é fiel! 
Consagre ao Senhor tudo o que você faz, e os seus planos serão bem-sucedidos.

Provérbios 16:3. 


\section{SUMÁRIO}

INTRODUÇÃO . . . . . . . . . . . . . . . 7

OBJETIVOS GERAL E ESPECÍFICOS $\ldots \ldots \ldots \ldots \ldots \ldots$

TRABALHOS CORRELATOS $\ldots \ldots \ldots \ldots \ldots \ldots \ldots \ldots$

PARADIGMAS, TECNOLOGIAS, EQUIPAMENTOS E SOLUÇÕES PARA AS APLICAÇÕES MÉDICAS $\ldots \ldots \ldots \ldots \ldots \ldots \ldots$ A INTERNET DAS COISAS (IOT) $\ldots \ldots \ldots \ldots \ldots \ldots$ A IOT NA ÁREA DE SAÚDE - SENSORES E REDE DE ÁREA CORPO-

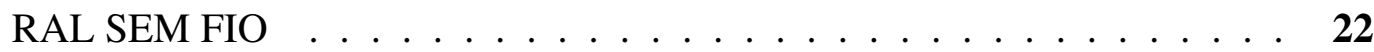
ESTRATÉGIA DE DISTRIBUIÇÃO DE DADOS PUBLISH/SUBSCRIBE (PUB/SUB) $\ldots \ldots \ldots \ldots \ldots \ldots \ldots \ldots \ldots \ldots \ldots \ldots$ PUBLISH/SUBSCRIBE E FOG COMPUTING . . . . . . . . . . . . 28 CIDADES INTELIGENTES NO CONTEXTO DA ÁREA DE SAÚDE . . . 29

ARCABOUÇO DE COMUNICAÇÃO DE DADOS IOT COM ESTRATÉGIA PUBLISH/SUBSCRIBE (PSIOT) $\ldots \ldots \ldots \ldots \ldots \ldots \ldots$ PSIOT - ASPECTOS BÁSICOS DA ARQUITETURA . . . . . . . . 31 PSIOT - MODELO DE TROCA DE MENSAGENS PUB/SUB E OPERAÇÃO 34

ARCABOUÇO DE COMUNICAÇÃO DE DADOS COM ESTRATÉGIA PUBLISH/SUBSCRIBE PARA APLICAÇÕES MÉDICAS (PSIOTHEALTH $\ldots \ldots \ldots \ldots \ldots \ldots \ldots \ldots \ldots \ldots \ldots \ldots$ GATEWAY E AGREGADOR DE DADOS MÉDICOS DO PSIOT-HEALTH 38

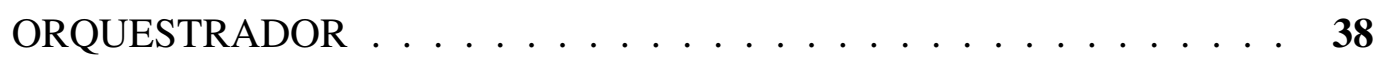
O CONSUMIDOR PUB/SUB . . . . . . . . . . . . . . . . . . . . . . . 39 PSIOT-HEALTH - ORQUESTRADOR E AGREGADOR PARA APLICAÇÕES MÉDICAS . . . . . . . . . . . . . . . . . . 39 O ORQUESTRADOR DO PSIOT-HEALTH . . . . . . . . . . . . . 40 O AGREGADOR DO PSIOT-HEALTH $\ldots \ldots \ldots \ldots \ldots \ldots \ldots$ DESENVOLVIMENTO DO CÓDIGO DO PSIOT-HEALTH $\ldots \ldots \ldots \ldots$

PROVA DE CONCEITOS - AMBIENTE DE TESTE E RESULTADOS 49 O AMBIENTE DE TESTE DO PSIOT-HEALTH $\ldots \ldots \ldots \ldots$. . . . . 49 RESULTADOS DO TESTE DE OPERAÇÃO DO PSIOT-HEALTH $\ldots \ldots \quad \mathbf{5 4}$ CONSIDERAÇÕES FINAIS $\ldots \ldots \ldots \ldots \ldots \ldots \ldots \ldots$ REFERÊNCIAS $\ldots \ldots \ldots \ldots \ldots \ldots \ldots \ldots \ldots \ldots$ 


\section{INTRODUÇÃO}

O aumento das populações e o processo de urbanização mundial traz um desafio no que diz respeito a oferecer serviços públicos de maneira eficiente. Diante disso, surge o conceito de cidades inteligentes, que visa enfrentar problemas relacionados a cidadania, tais como: saúde, segurança pública, energia, desenvolvimento econômico, serviços sociais, entre outras (ZHANG et al., 2020) (BEZERRA; MARISTELA; MARTINS, 2015) (SOLANAS et al., 2014).

O número de pessoas nos grandes centros urbanos com necessidade de cuidados de saúde, como idosos, deficientes e pacientes com mobilidade reduzida, aumentou consideravelmente em diversos países. Isso gera a necessidade de termos soluções que possam atender esse grupo de pessoas que tem, em princípio, mobilidade reduzida e que, por decorrência, precisam ser atendidos nos seus respectivos locais de residência.

Existem soluções da área de saúde que viabilizam o atendimento personalizado e no local de permanência do paciente como, por exemplo, o atendimento na residência (home care). No entanto, entende-se que as tecnologias atualmente existentes de coleta de dados e de comunicação podem fornecer um novo tipo de serviço onde o atendimento vai até o paciente de forma não presencial. Uma das alternativas para o atendimento in loco são os sistemas inteligentes de saúde residencial, ou Health Smart Homes (HSH) (MSHALI et al., 2018). Este tipo de solução é uma das tendências na área de aplicações médicas distribuídas e aplicações médicas suportada pela web (e-Health) de maneira geral. Do ponto de vista da visão geral do atendimento médico próximo ao paciente, observa-se que estes precisam de monitoramento e, baseado nestes dados coletados, cuidados médicos em suas residências (NETO et al., 2017). O foco principal desta dissertação é então o suporte ao monitoramento dos dados de pacientes em seus locais de residência fazendo uso de tecnologias específicas de coleta de dados e de comunicação via rede.

Nesse contexto, sensores e dispositivos de coleta de dados médicos (XU; XU, 2017), sistemas de acompanhamento (CHORBEV et al., 2017) e sistemas de diagnóstico médico (GUERREIRO, 2017) são desenvolvidos a fim de fornecer serviços relacionados à saúde, para, entre outras coisas, trazer conforto a pacientes e maior capilaridade na ação dos médicos através do monitoramento em tempo real, sistema de gerenciamento de informações do paciente e sistema de gerenciamento de saúde (SEBESTYEN et al., 2014).

Na consecução destes sistemas distribuídos de apoio à saúde existem alguns elementos essências na composição da solução, como segue:

- Um conjunto de sensores e dispositivos de coleta de dados próximos ou afixados no paciente;

- Uma estrutura de comunicação para transportar os dados coletados entre o paciente e o sistema de apoio médico desenvolvido; e 
- Uma estratégia de distribuição dos dados coletados através do sistema de comunicação utilizado.

A internet das coisas (Internet of Things - IoT) engloba o conjunto de sensores, atuadores, equipamentos e sistemas que são distribuídos e podem coletar dados e atuar de forma ubíqua visando algum tipo de resultado ou produto para os seres humanos ou para a sociedade (JAVED et al., 2018). Neste conjunto geral de sensores e atuadores IoT os sensores e dispositivos médicos constituem uma família específica de dispositivos que são os utilizados nas aplicações médicas distribuídas, foco da solução desenvolvida nesta dissertação.

A internet das coisas apresenta uma tendência de grande crescimento e, por decorrência, tem a característica de estar omnipresente de maneira global (CHETTRI; BERA, 2020) (BEZERRA; MARISTELA; MARTINS, 2015). A característica onipresente da IoT torna viável que os sistemas de saúde e seus componentes (indivíduos, aparelhos, medicamentos) possam ser monitorados e gerenciados continuamente (RAHMANI et al., 2018). Nesse contexto, as coisas se referem a atuadores ou sensores que trabalham nesse cenário para colaborar com o processo de recuperação de pessoas em casa, coletando e enviando informações necessárias acerca de características e do estado do paciente (NETO et al., 2017).

As redes e tecnologias de comunicação de dados são uma realidade mundial e estão fortemente presentes nos grandes centros urbanos e, principalmente, no contexto das cidades inteligentes. No contexto das cidades inteligentes existe, além das redes, a necessidade de utilização de novos paradigmas e tecnologias dada a complexidade, distribuição e volume de dados envolvidos (Smart City) (MARTINS, 2018). No contexto do trabalho desta dissertação, a utilização do paradigma Pub/Sub é um exemplo deste tipo de necessidade nas cidades inteligentes.

Nesse cenário de aplicações médicas distribuídas em cidades ou de uma outra forma, não é mais suficiente apenas projetar os sensores ou os dispositivos vestíveis ou corporais autônomos. No caso, faz-se necessário criar um ecossistema para que esses sensores transmitam os dados necessários por meio da uma infraestrutura que faz uso da IoT e de outros mecanismos (RAHMANI et al., 2018).

Os sistemas de publicação/ assinatura (Publish/Subscribe), também denominados de $\mathrm{Pub} / \mathrm{Sub}$, fazem de maneira geral a intermediação entre produtores e consumidores de dados através de um sistema de publicação de anúncios/ informações e de troca de mensagens visando a obtenção de dados. O paradigma Pub/Sub gerencia a comunicação entre produtores e consumidores de forma assíncrona, garantindo a entrega das informações requisitadas por cada consumidor de dados (NOUR et al., 2019).

Um outro paradigma usado tipicamente na IoT, a computação nas pontas (Fog Computing), pode ser igualmente utilizado quando a aplicação permite e se deseja economizar energia e reduzir a latência e o volume de dados entre produtores e consumidores numa estratégia Pub/Sub (NETO et al., 2017). O fog computing, em resumo, define uma estratégia onde 
o processamento dos dados é realizado na borda da rede e próximo do produtor dos dados (MUKHERJEE; SHU; WANG, 2018) (NETO et al., 2017).

A Figura 1 representa um modelo genérico para um sistema de monitoramento remoto da saúde humana, com os seus principais componentes envolvidos em atividades como: coleta de dados, gerenciamento dos dados, fusão e distribuição dos dados (SILVA, 2013).

Figura 1 - Sistema típico de monitoramento remoto da saúde humana.

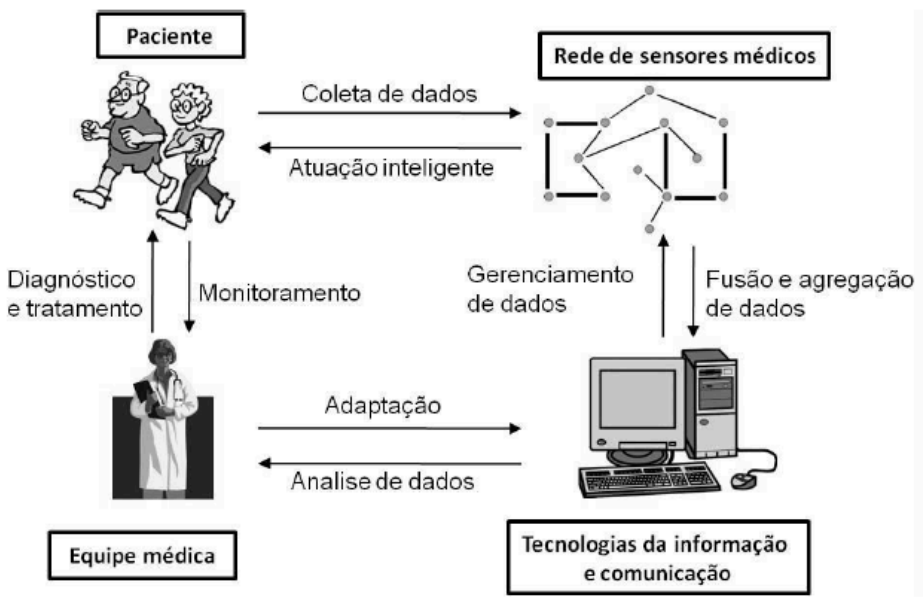

Fonte: NETO e TATEYAMA (2018).

Alguns dos desafios envolvidos na implementação de uma aplicação médica distribuída são objeto do desenvolvimento realizado por esta dissertação.

A proposta básica da solução desenvolvida nesta dissertação é o suporte para a implantação de aplicações médicas distribuídas, por exemplo, no contexto de uma cidade inteligente. Este suporte é viabilizado através da criação de um arcabouço de suporte à comunicação entre a aplicação médica e o conjunto de sensores que monitoram o estado de pacientes. $\mathrm{O}$ arcabouço proposto lida com a questão da produção e distribuição dos dados médicos utilizando o paradigma Publish/Subscribe e gerencia a comunicação de dados médicos de monitoração através de uma rede entre os produtores e consumidores de dados médicos.

\subsection{OBJETIVOS GERAL E ESPECÍFICOS}

O objetivo geral desta dissertação de mestrado é o desenvolvimento de um arcabouço de comunicação de dados baseado no modelo Publish/Subscribe para o suporte à coleta e distribuição de dados de aplicações médicas distribuídas.

Os objetivos específicos do trabalho são os seguintes:

- Desenvolvimento de um arcabouço Pub/Sub denominado PSIoT-Health (Publish/Subscribe 
for Internet of Things and Health Applications) a partir da adaptação e complementação de código e de funcionalidades de um arcabouço Pub/Sub existente, denominado PSIoT (Publish/Subscribe for Internet of Things); e

- Desenvolvimento de uma solução de comunicação de dados usando o modelo de mensagens do Pub/Sub e algoritmos de gestão da produção e da distribuição de dados orientados para os requisitos específicos das aplicações médicas distribuídas. 


\section{TRABALHOS CORRELATOS}

A seguir serão apresentados alguns trabalhos correlatos existentes na literatura e dois exemplos de aplicações voltadas ao setor de saúde que influenciaram na construção do PSIoTHealth.

Esse aplicativos são:

- Weartool (THAMAY; MORAIS, 2018); e

- Sistema para monitoramento da Saúde (OTTO; JOVANOV; MILENKOVIC, 2006).

O Weartool tem como objetivo monitorar pessoas idosas que podem sofrer quedas. $\mathrm{O}$ Weartool foi desenvolvido para ser uma plataforma de desenvolvimento de aplicações para dispositivos móveis, com o propósito de realizar o controle e a configuração de sensores. Ele recolhe os dados enviados pelos sensores e decide, a partir destes, quais situações configuram uma queda. Caso o aplicativo identifique que o idoso caiu, um alerta é enviado ao smartphone de uma pessoa indicada como cuidadora do idoso.

O sensor utilizado no projeto, chamado de MetaDetector, é alimentado por uma pequena bateria de lítio CR2032 com tensão de 3V. O sensor é constituído por: acelerômetro, fotosensor, sensor de proximidade e sensor de temperatura (termistor). Além desses componentes, há também um botão para ser usado nas situações em que o idoso se sinta em perigo. Ao pressioná-lo, uma notificação de alerta é enviada aos seus médicos ou responsáveis. A função do sensor é enviar informações referentes à movimentação do idoso e eventualmente alertar o aplicativo via Bluetooth. Ele pode ser afixado em qualquer tecido, o que facilita a sua colocação em roupas.

A identificação de quedas é realizada por um giroscópio e por um acelerômetro contidos no MetaDetector. O primeiro mede a taxa de rotação, o segundo detecta a aceleração linear, mensurando a orientação dos segmentos do corpo humano através de uma Unidade de Medição Inercial (IMU). A IMU é um dispositivo utilizado em equipamentos que precisam da informação de sua posição exata, pois, ele mede e descreve a taxa angular e a força específica em um corpo.

Em um acelerômetro de três dimensões, as curvas X, Y e Z geralmente obedecerão a um grau de sintonia. Ao acontecer qualquer tipo de queda, os três eixos irão sofrer variações. Logo, pode-se constatar que quando as três dimensões sofrem um pico e tendem ao repouso de forma sincronizada há altas chances de significar uma queda.

As Figuras 2 e 3 são resultados de simulações utilizando o MetaDetector, na Figura 2, o gráfico mostra as variáveis $\mathrm{x}, \mathrm{y}$ e $\mathrm{z}$ em comportamento linear, representando o idoso em repouso. 
Figura 2 - Idoso em repouso

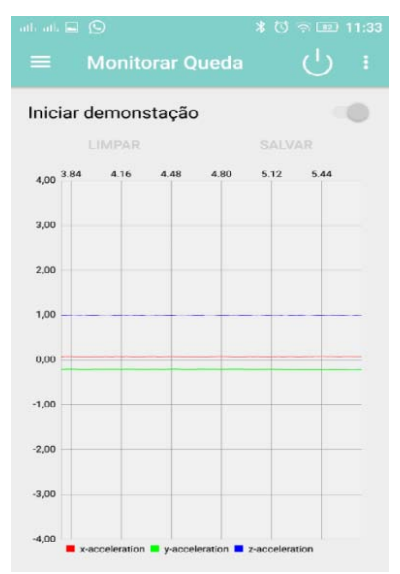

Fonte: THAMAY e MORAIS (2018).

Na Figura 3, onde uma queda é simulada, pode-se observar que quando o idoso estava dando uma caminhada, do inicio do gráfico até o intervalo de $13.73 \mathrm{~s}$, os valores das variações de aceleração eram pequenos. Posteriormente, a causa ou o movimento que antecedeu a queda fez com que esses números crescessem no intervalo entre $13.73 \mathrm{~s}$ e $14 \mathrm{~s}$.

Figura 3 - Idoso em queda

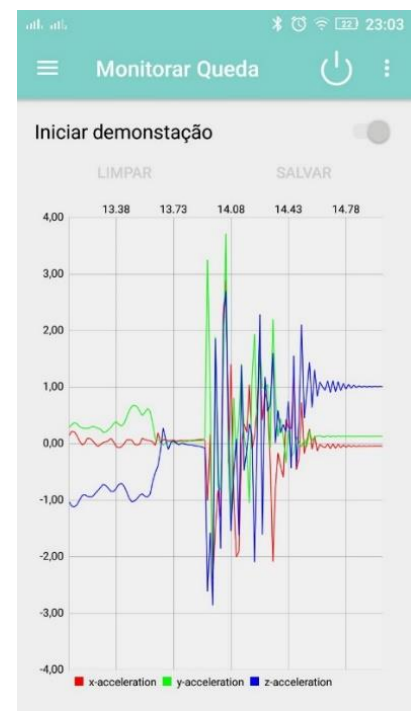

Fonte: THAMAY e MORAIS (2018).

O momento da queda, que aconteceu no intervalo entre $14 \mathrm{~s}$ a $14.43 \mathrm{~s}$, causou um aumento ainda maior da aceleração nos eixos x, y e z e em seguida, a partir dos $14.5 \mathrm{~s}$, tendeu ao repouso.

Os resultados apresentados mostram que através de um dispositivo compacto, de baixo custo, de fácil utilização e oriundo do contexto da internet das coisas, consegue-se obter características físicas e caracterizar, por exemplo quedas. 
Uma arquitetura para um sistema de monitoramento de saúde baseado em WBAN (Wireless Body Area Network) com o objetivo de realizar o acompanhamento domiciliar de pacientes que estejam em reabilitação cardíaca é apresentada em (OTTO; JOVANOV; MILENKOVIC, 2006).

Nesta aplicação sensores sem fio são colocados em lugares estratégicos do corpo do paciente para coletar, processar e armazenar informações relacionadas a características fisiológicas. Eles se comunicam diretamente com um gateway WBAN, cuja o papel é encaminhar dados para um servidor (doméstico ou médico) e sincronizar a transmissão de informações, como ilustrado na Figura 4.

Figura 4 - Sistema de monitoramento da saúde em casa

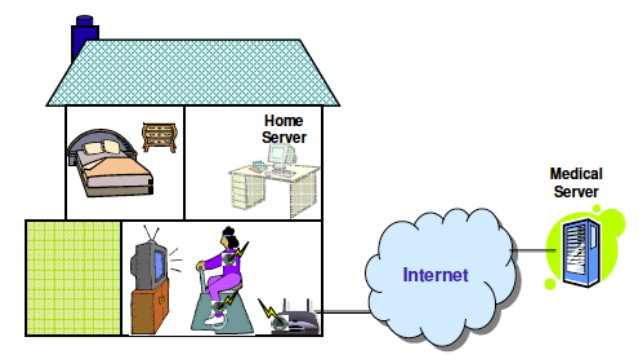

Fonte: OTTO, JOVANOV e MILENKOVIC (2016).

O servidor doméstico tem como objetivo gerar os arquivos de sessão de monitoramento do usuário e fornecer retornos sobre esses dados para os pacientes. Quando o usuário sai do intervalo de alcance do gateway WBAN, os sensores armazenam os dados localmente num buffer. Quando o paciente retorna, o enlace WBAN é restabelecido e todas as informações anteriormente armazenadas são enviadas. O protótipo desenvolvido utiliza um sensor cardíaco para monitorar a atividade cardíaca, e um sensor de movimento.

O sensor de movimento tem como função estimar a intensidade e diferenciar os estados de atividades do usuário, tais como deitar, caminhar, correr, sentar, etc. Quanto mais sensores de movimento estiverem implantados melhor é a estimativa da atividade do paciente. O local de alocação desses dispositivos depende do objetivo da aplicação, ou seja, do tipo de característica fisiológica que será explorada.

Uma plataforma sem fio padrão é utilizada para implementar o gateway WBAN e por fim, em um computador pessoal, é executado o aplicativo do servidor de saúde doméstico.

Como ilustrado na Figura 5, o pico do aumento da frequência cardíaca (heart rate) e do gasto energético induzido por atividade (Activity Anergy Expenditure - AEE) se da quando o usuário começa uma corrida lenta e, ao voltar a ficar sentado, esses números diminuem. 
Figura 5 - Comportamento do AEE e da frequência cardíaca em diferentes atividades físicas

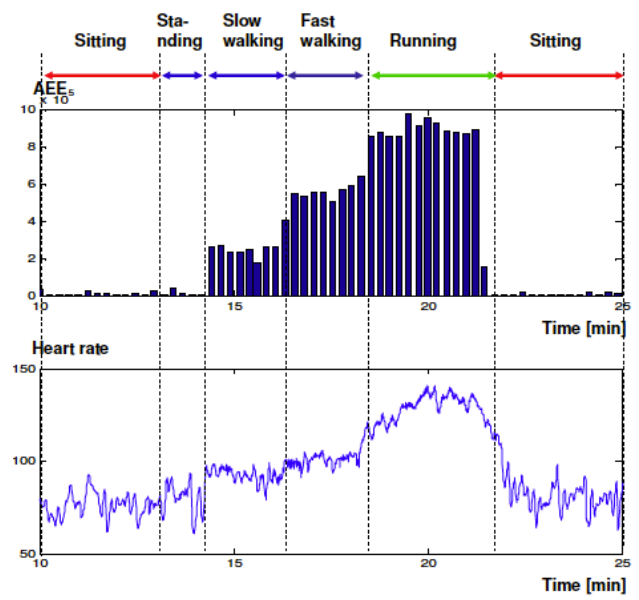

Fonte: OTTO, JOVANOV e MILENKOVIC (2016).

Estas aplicações ilustram alguns aspectos funcionais que serão objeto do PSIoT-Health tais como a necessidade de coletar e selecionar dados, a diferenciação entre tipos de dados, a necessidade de agregar e armazenar dados e a necessidade de transferir dados por uma rede para que possam ser processados.

Uma discussão sobre a arquitetura de gateways, no estilo do gateway utilizado no PSIoTHealth para internet das coisas), é apresentada em (ZHONG; ZHU; HUANG, 2015).

No que diz respeito à comunicação entre sensores e entre o sensor o o gateway (JAMEEL et al., 2018) discute as tecnologias de comunicação equipamento-para-equipamento (Device-to-Device - D2D ) ilustrando as suas várias alternativas.

Uma discussão sobre o problema de alocação de recursos de comunicação e de processamento em nuvem com processamento dos dados IoT nas pontas (edge) num estilo fog computing como ocorre com o PSIoT-Health é apresentado de forma abrangente em (WU et al., 2020). 


\section{PARADIGMAS, TECNOLOGIAS, EQUIPAMENTOS E SOLUÇÕES PARA AS APLICAÇÕES MÉDICAS}

Esta dissertação utiliza um conjunto de tecnologias e aspectos teóricos que são resumidas a seguir visando facilitar o entendimento da solução PSIoT-Health desenvolvida.

\subsection{A INTERNET DAS COISAS (IOT)}

Estima-se que termo "internet das coisas"foi apresentado primeiramente em 1999 por Kevin Ashton durante uma palestra realizada na Procter Gamble (PG) sobre as etiquetas RFID (Radio Frequency Identification) e sua utilização em uma grande cadeia de suprimentos (ASHTON et al., 2009).

Ashton et al. (2009) compartilhou o seguinte argumento durante a sua apresentação: os seres humanos atualmente (1999) criam e capturam todos os dados disponíveis na internet, porém, as pessoas são limitadas nos quesitos atenção, tempo e precisão, portanto, elas não são muito boas em capturar dados sobre coisas no mundo real e em contrapartida a isso, nós, assim como o nosso ambiente, somos físicos e consequentemente a nossa economia, sociedade e sobrevivência são pautadas não apenas em ideias mas também em coisas, por isso precisamos de máquinas detentoras desse conhecimento.

Treze anos mais tarde, em 2012, a União Internacional de Telecomunicações (UIT) definiu a IoT como:

uma infraestrutura global para a Sociedade da Informação, permitindo serviços avançados por meio da interconexão (física e virtual) de coisas baseadas em tecnologias de informação e comunicação interoperáveis existentes e em evolução (GROUP et al., 2012).

Em 2015, Madakam et al. (2015) definiu IoT a partir do conceito das duas palavras que a forma: "internet"e "coisa". Ele define internet como:

Um sistema global de redes de computadores interconectadas que usam o conjunto padrão de protocolos de Internet (TCP/IP) para atender bilhões de usuários em todo o mundo.

Madakam et al. (2015) considera que um conjunto de tecnologias de rede eletrônica, óptica e sem fio, interligam milhões de redes privadas, públicas, acadêmicas, empresariais e governamentais que juntas, formam a internet. Em relação ao conceito de coisa, ele define que:

Podem ser qualquer objeto ou pessoa que possa ser distinguida pelo mundo real. 
Madakam et al. (2015) julga que as coisas não são necessariamente equipamentos eletrônicos avançados. Seres vivos ou objetos que usamos em nosso dia a dia, tais como: animais, plantas, roupas, móveis, obras de arte etc. também podem ser considerados coisas.

Kopetz (2011) baseia a internet das coisas na conexão das coisas físicas à internet, pois isso permite o acesso de dados remotos provenientes de sensores, ou seja, possibilita o controle do mundo físico à distância. Ele exemplifica a sua consideração relatando que a soma de dados capturados de sensores e dados retirados da internet pode dar origem a novos serviços que não seriam possíveis sem essa comunicação.

Em 2017 Albertin e Albertin (2017) conceituou a Internet das Coisas (Internet of Things - IoT) como uma rede de alcance potencialmente global, com características de ubiquidade que possibilita a interconexão de coisas através da coleta, do processamento e da análise de dados por meio de uma rede como, por exemplo, a Internet.

A figura abaixo mostra a evolução da IoT ao longo do tempo:

Figura 6 - Evolução da IoT

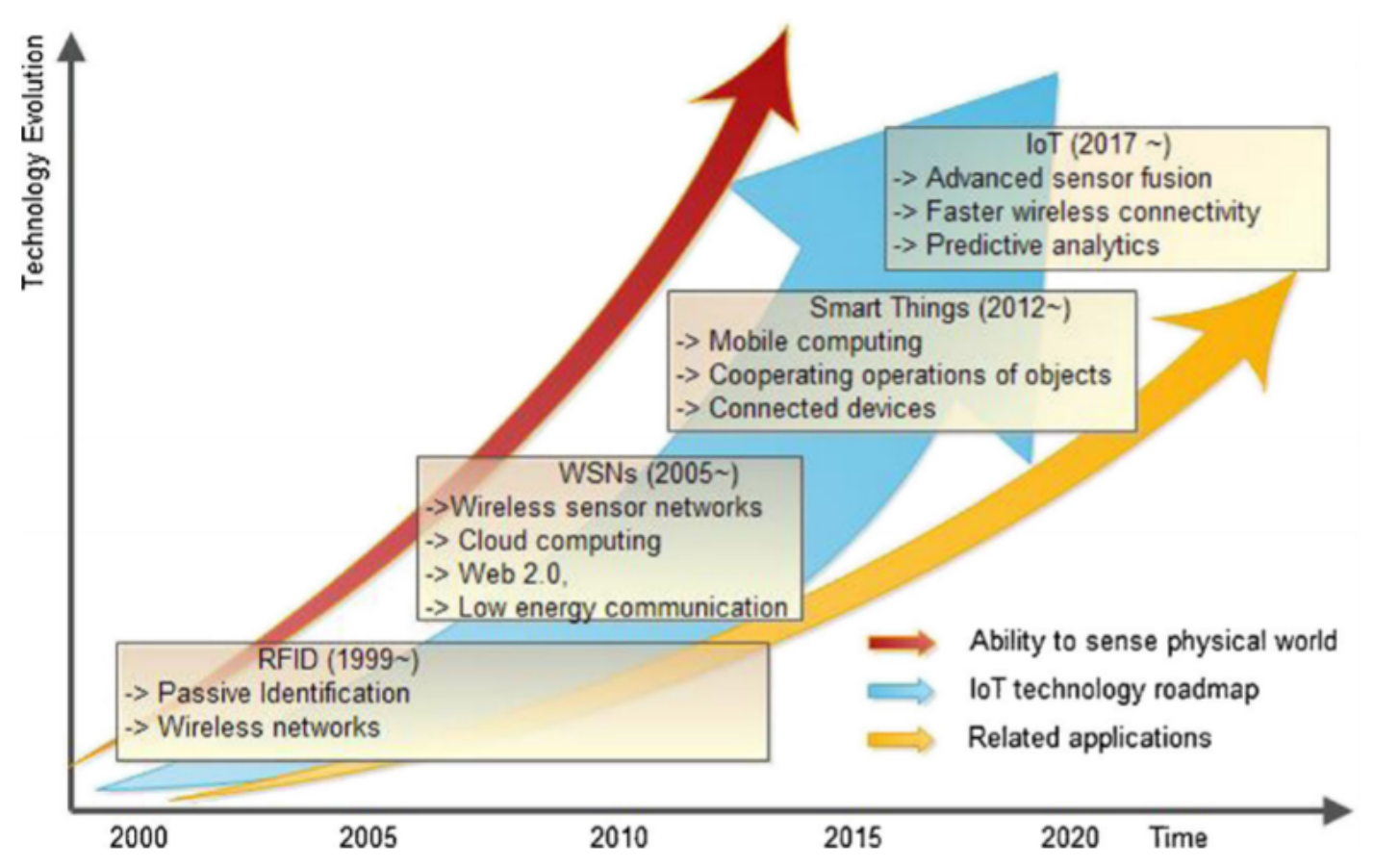

Fonte: LI, XU e ZHAO (2015).

Começou-se a falar em IoT em 1999, com a inserção da tecnologia RFID em vários tipos de indústrias. Por volta de 2005 surgiram as Redes de Sensores Sem Fio que aumentaram a capacidade sensorial dos dispositivos, permitindo identificação e o acesso à internet dos mesmos. Os avanços das redes de sensores sem fio ao longo do tempo resultaram no surgimento e propagação das coisas inteligentes (2012), cuja a difusão se deve principalmente a evolução da 
computação móvel. A partir de 2017 a IoT foi deixando de ser vista como um conceito abstrato e se tornou um passo real, onde já era possível obter conexões sem fio rápidas e fazer análises preditivas com diversos tipos de dados (LI; XU; ZHAO, 2015). Atualmente (2020), existem muitas pesquisas e aplicações baseadas em IoT, empresas e governos estão investindo nesse tipo de ferramenta para aperfeiçoar os seus processos e melhorar a qualidade de vida dos seus cidadãos.

A figura abaixo representa a estrutura proposta por esse trabalho para a Internet das coisas dentro do conjunto de uma cidade, onde as "coisas"podem representar sensores, atuadores, equipamentos e sistemas de maneira geral que são utilizados, dentro de uma estrutura, tanto para captar inúmeros tipos de informações como atuar em relação aos sistemas físicos e virtuais.

Figura 7 - Internet das Coisas .

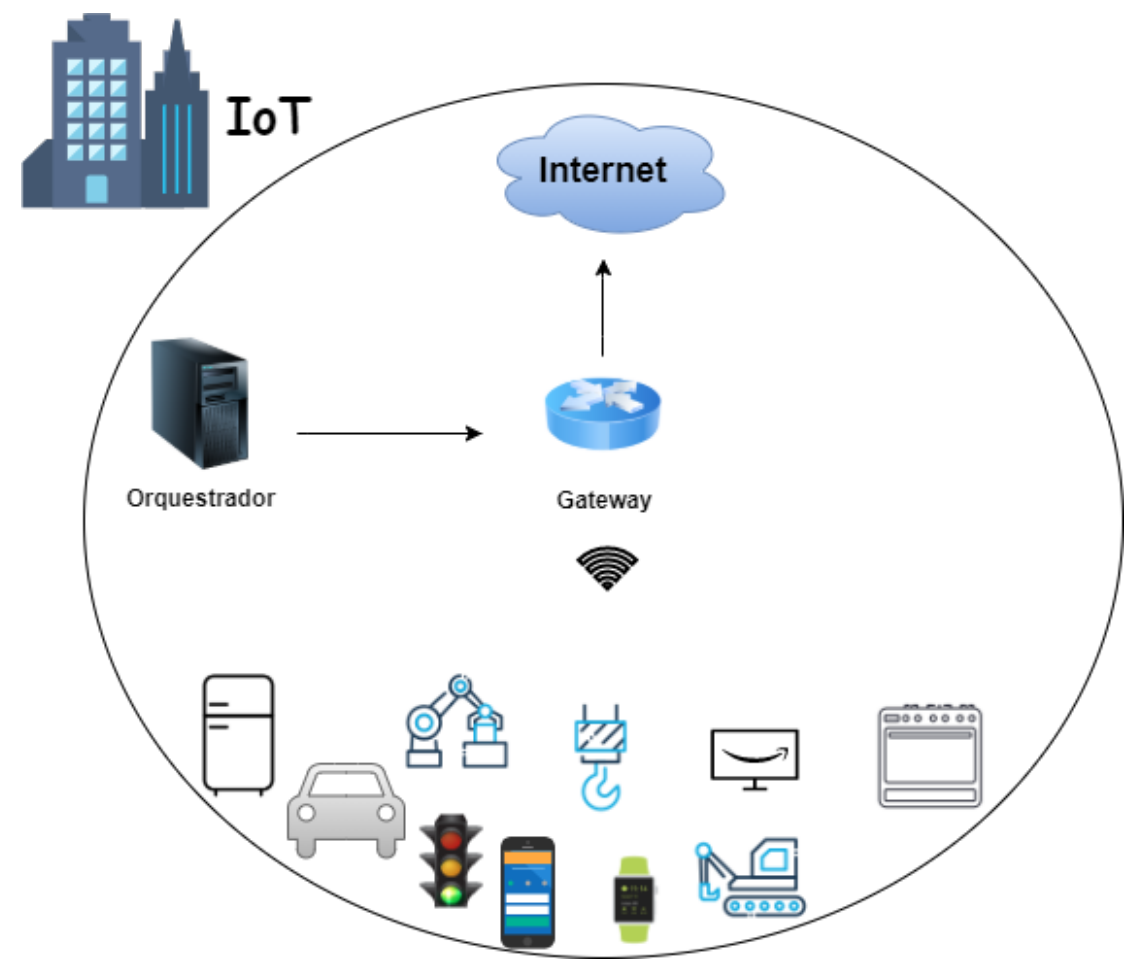

A IoT aumenta a onipresença da Internet ao integrar todos os objetos para interação por meio de sistemas embarcados, o que leva a uma rede altamente distribuída de dispositivos que se comunicam não apenas com seres humanos (Homem para coisa) mas também com outros equipamentos (Coisa para coisa) (XIA et al., 2012).

O fenômeno da interação Homem-Coisa (H2T) citado acima, pode ser entendido como a interação entre o sistema computacional e um usuário (pessoa). Ou seja, a H2T constituise da colaboração entre máquina e ser humano para a execução de uma determinada tarefa (COSTALONGA et al., 2014). Enquanto o estilo de comunicação T2T pode ser descrito como a comunicação entre duas máquinas ou o envio de informações de uma máquina para outra 
máquina central através de uma solução de comunicação, como uma rede (com ou sem fio) (MARTINS; GONÇALVES, 2017).

A figura abaixo demonstra a nova realidade das TICs (tecnologias de informação e comunicação) após o advento da T2T. Nesse novo contexto começamos a ter conectividade de qualquer lugar, para qualquer coisa e em qualquer tempo (TAN; WANG, 2010).

Figura 8 - Realidade T2T

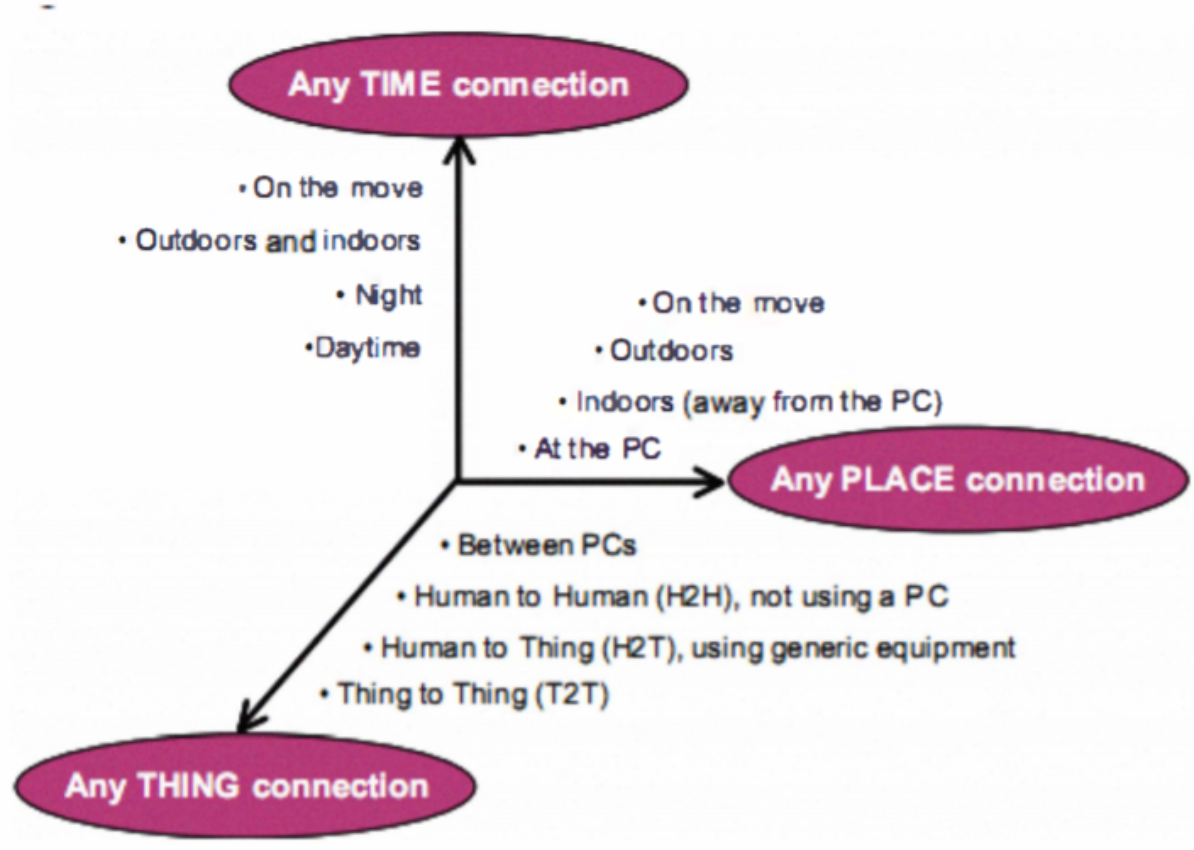

Fonte: TAN e WANG (2010).

O crescente desenvolvimento da IoT utilizando essas formas de comunicação, gerou uma grande busca e utilização dos dispositivos inteligentes, principalmente por parte das grandes empresas, pois, a possibilidade de seguir objetos através das cadeias de commodities em que estão incorporados proporciona: aceleramento de processos, redução de erros, diminuição de roubos, eficiência e a incorporação de sistemas organizacionais complexos e flexíveis. (MADAKAM et al., 2015).

Conforme essa procura aumenta, lacunas relativas a infraestrutura, comunicação, normas, protocolos, etc. também são geradas (LI; XU; ZHAO, 2015). Por exemplo: dentro do contexto da IoT surge a necessidade de se ter protocolos apropriados para possibilitar a troca de dados fim-a-fim entre um ou mais dispositivos autônomos com pouca ou nenhuma intervenção humana (MAIA, 2013).

de se ter protocolos apropriados para gerenciar esse tipo de comunicação, ou seja, para possibilitar a troca de dados fim-a-fim entre um ou mais dispositivos autônomos com pouca ou 
nenhuma intervenção humana (MAIA, 2013).

Normalmente, as aplicações IoT utilizam um grande número de dispositivos com recursos limitados, baixo custo e que podem se comunicar utilizando uma variedade de tecnologias. Esses elementos podem ser, por exemplo, sensores e etiquetas RFID utilizando tecnologias de rede como Bluetooth (CHEN et al., 2019) e o WiFi (IEEE 802.11) (CHEN et al., 2019). As limitações de recursos incluem uma disponibilidade limitada de energia provida por uma bateria e uma capacidade de processamento e de armazenamento limitadas (MASEK et al., 2016).

Alguns fatores são essenciais para a crescente utilização da internet das coisas (PACHECO; KLEIN; RIGHI, 2016):

- A redução do tamanho do hardware de maneira geral e, especialmente, dos sensores e atuadores;

- O aumento do poder de processamento dos microprocessadores;

- A melhoria da confiabilidade e a redução do custo do hardware; e

- O avanço das soluções de rede.

A IoT, de maneira geral, proporciona uma capacidade computacional e de comunicação para objetos do dia-a-dia, possibilitando que estes tomem decisões sem instruções explícitas, tendo como com base as informações sobre as necessidades e requisitos dos usuários (DOHR et al., 2010).

Como exemplo, uma geladeira com acesso à internet pode avisar quando um alimento está perto de acabar e, ao mesmo tempo, pesquisar por melhores preços para aquele item. Um relógio que, tipicamente, apresenta as horas, agora pode receber chamadas telefônicas, notificações de redes sociais e e-mail e capturar dados médicos do usuário. Nesse último caso, o processamento no relógio pode, por exemplo, constatar e notificar quando uma pessoa está sedentária ou está um situação crítica a ponto de merecer atenção médica (GOMES; BERGAMO, 2018).

Embora existam diversas possibilidade de modelagem, tipicamente, a arquitetura IoT consiste em quatro camadas (LEE; BAE; KIM, 2017):

- Camada de serviço;

- Camada de plataforma;

- Camada de rede; e

- Camada de dispositivo. 
A Figura 9 ilustra estas camadas exemplificando os diversos componentes que cada uma pode conter:

Figura 9 - Camadas da arquitetura IoT.
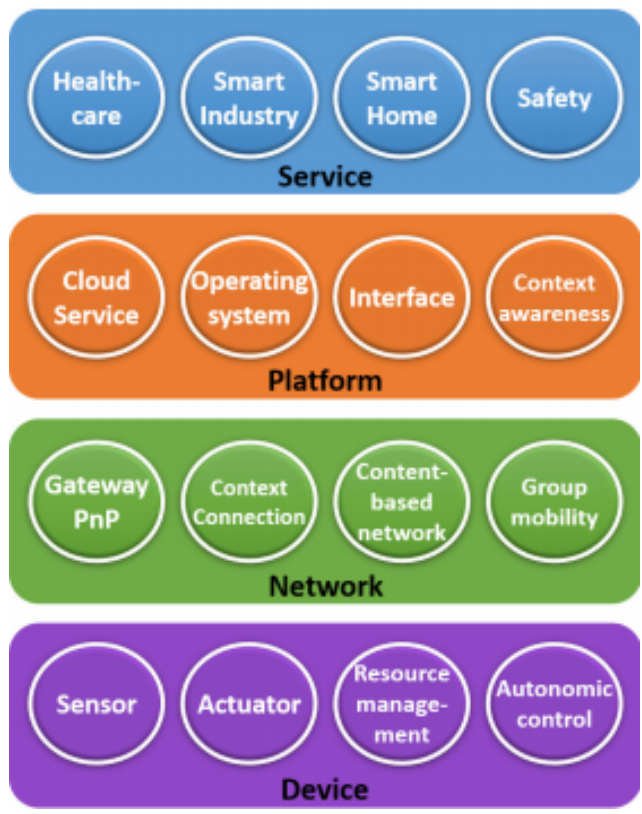

Fonte: LEE, BAE e KIM (2006)

A camada de serviço faz a interface com o usuário, fornecendo uma interface de comunicação com o cliente para responder diretamente às necessidades do mesmo. Alguns serviços pertencentes a essa camada incluem as facilidades específicas que são necessárias para o desenvolvimento das aplicações em diversas áreas como as casas inteligentes, indústria inteligente e dispositivos pessoais.

A camada de plataforma oferece os recursos computacionais para a execução dos serviços e suas aplicações. Existem diversos tipos de plataformas, tais como: plataforma de análise de dados, plataforma de desenvolvimento de serviço e plataforma de serviço, dentre outras. A plataforma de dispositivos, por exemplo, fornece ferramentas de desenvolvimento para que programadores possam desenvolver aplicações da IoT vinculadas à dispositivos de maneira geral. Exemplos de tipos de plataformas incluem os sistema operacional, os serviço na nuvem, interfaces e sistema de apoio ao desenvolvimento baseados em contexto.

A camada de rede, como o nome indica, é utilizada para transmitir os dados entre dispositivos IoT e aplicações IoT que controlam, desenvolvem e gerenciam conteúdos, serviços e usuários. A camada de rede deve ser capaz de transferir quantidades muito grandes de dados dado a enorme aplicabilidade e utilização de sensores e atuadores IoT nos mais diversos cenários de aplicação.

A camada de dispositivo existe no nível físico dos equipamentos e, basicamente, coleta e 
envia dados para o ambiente através de vários dispositivos. A interface com o nível físico da IoT é tipicamente implementado através de gateways. Este equipamento e seus dispositivos coletam dados, atuam no ambiente e possuem, eventualmente, alguma capacidade de processamento dos dados coletados (LEE; BAE; KIM, 2017).

$\mathrm{O}$ arcabouço de comunicação Publish/Subscribe para a coleta de aplicações médicas utilizou a arquitetura IoT e suas interações como base na sua estrutura ilustrada a seguir:

Figura 10 - Interações do PSIoT-Health.

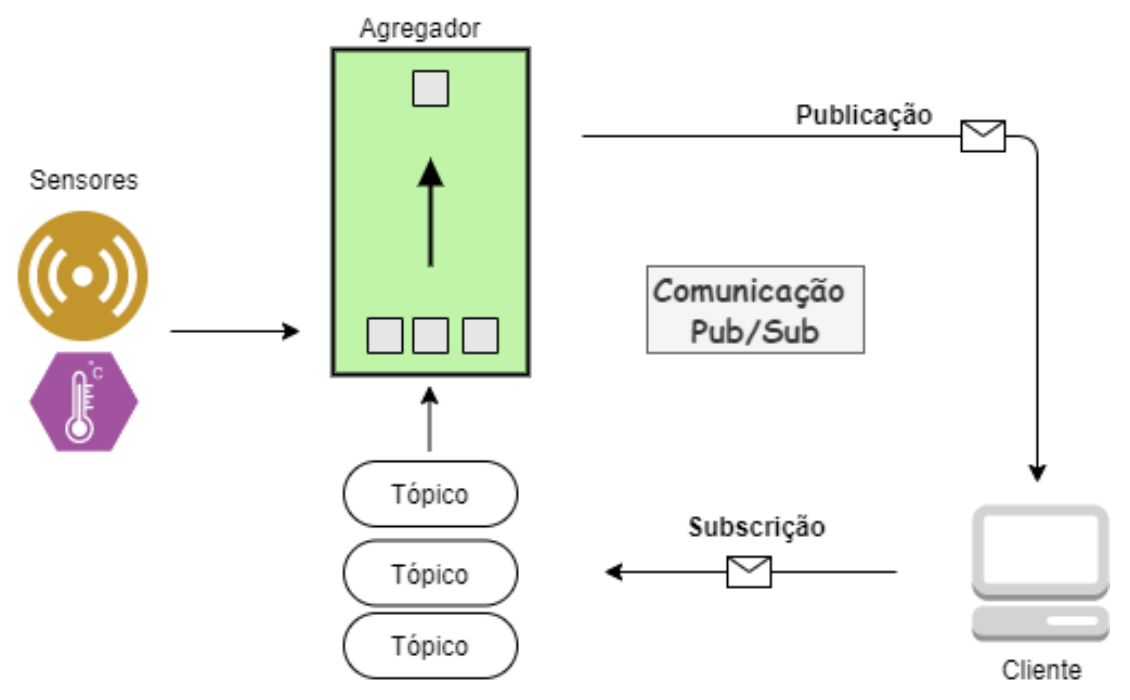

Pode-se observar na Figura 10 que os sensores enviam seus dados de maneira unilateral para o agregador, que por sua vez, realiza o agrupamento e pré-processamento desses dados.

O agregador também possui outros dois tipos de interações: uma recebendo as inscrições dos clientes e a outra quando publica as informações solicitadas.

Em relação aos ao clientes, todas as suas interações são intermediadas pelo padrão de mensagens do Publish/Subscriber. É através desse estilo de comunicação que o cliente expressa o que quer (através de suas inscrições por tópico) e recebe os dados solicitados.

As camadas e estruturas de interações desenvolvidas já demonstram uma consolidação da IoT que só tende a crescer, mas para isso, para que a IoT consiga ser acessível para uma grande parcela da população, alguns desafios ainda precisam ser superados, como por exemplo, a heterogeneidade dos seus dispositivos que dificulta a comunicação entre os seus elementos (SANTOS et al., 2016).

Outra grande necessidade da IoT é garantir segurança em seu ambiente. Visto que segurança na Internet já é um assunto preocupante, na IoT, torna-se ainda mais desafiadora pois o número de dados manipulados em questão cresce exponencialmente (REYNA et al., 2018).

Alguns autores apontam que a IoT será a nova revolução da tecnologia da informação. Sendo assim, a IoT possivelmente não deve ser entendida como um fim, mas sim um meio de 
alcançar algo maior através da computação ubíqua (SANTOS et al., 2016). A grande questão é a rapidez com que essa tecnologia está se difundindo, dia pós dia, cada vez mais fazendo parte da vida das pessoas. É sabido que toda grande mudança gera impactos, positivos ou negativos, mas ainda é cedo para mensurar as consequências da adoção da IoT pela sociedade (LACERDA; LIMA-MARQUES, 2015).

\subsection{A IOT NA ÁREA DE SAÚDE - SENSORES E REDE DE ÁREA CORPORAL SEM FIO}

No contexto do PSIoT-Health, objeto do desenvolvimento desta dissertação, os sensores corporais e a sua comunicação de maneira geral são uma informação de contexto relevante e, assim sendo, será feito um breve relato das soluções disponíveis para a área e suas características principais.

É importante também ressaltar que os sensores e eventuais atuadores usados no contexto especifico das redes corporais são mais um exemplo da internet das coisas (IoT) com um foco mais direcionado para a área de saúde.

Uma rede corporal sem fio (Wireless Body Area Network - WBAN) é formada por sensores conectados ou implantados no corpo humano e que são capazes de estabelecer um enlace de comunicação de dados sem fio visando a troca de informações de coleta e de controle. Estes sensores são tipicamente utilizados para fazer a coleta de dados corporais de pessoas e têm como objetivo principal monitorar a condição de um ou mais parâmetros corporais (PRAMANIK; NAYYAR; PAREEK, 2019).

No caso específico da área de saúde, o sensor é um dispositivo pequeno, de alguns milímetros formado por um rádio transmissor, uma bateria e um processador, responsável por captar grandezas físicas, como temperatura do corpo, batimentos cardíacos, etc. Ele pode ser implantado externa (extra-body) ou internamente (intra-body) ao corpo humano ou pode fazer parte de uma veste especial (PRAMANIK; NAYYAR; PAREEK, 2019).

Os sensores são cada vez menores para garantir mobilidade e comodidade ao utilizador, contudo, impõem um desafio no quesito eficiência energética. Um sensor de pequeno tamanho, consequentemente possui uma bateria pequena. A duração da bateria é proporcional ao tamanho e, via de regra, não dura muito em um sensor pequeno e esse é um dos pontos críticos da questão.

A solução que se busca em termos de consumo de energia para uma WBAN é a combinação de um menor consumo com a maior duração possível para a bateria. As WBAN devem detectar, processar e comunicar dados de maneira eficiente em termos de energia. Isso é particularmente importante para os sensores (intra-body), onde a necessidade de substituição da bateria soma custos e desconforto para o utilizador.

Outro ponto importante em uma WBAN é o encaminhamento de dados e este aspecto tem relação direta com o trabalho desenvolvido. As informações acerca das medidas corporais 
devem ser encaminhadas a um sistema especialista, para então, o mesmo enviar uma resposta com algum tipo de diagnóstico. Dependendo do objetivo da aplicação, esse processo deve ser necessariamente executado em tempo real e com um requisito de prioridade entre os dados coletados. Este ponto em particular é um dos objetivos do arcabouço PSIoT-Health desenvolvido.

De maneira geral, a comunicação entre o sensor e a aplicação de processamento e controle pode ser prejudicada devido a atenuação do sinal de rádio ou pelo tráfego existente para a troca dos dados, Esse fato acaba requerendo que algum nível de prioridade possa ser atribuído aos dodos sendo transmitidos e este aspecto é também um elemento considerado no PSIoTHealth, objeto desta dissertação.

Quando se trata de dispositivos implantados sob a pele esse quadro é ainda mais desafiador. O nosso corpo (composto de $70 \%$ de água) se torna um empecilho para a transmissão e recepção dos sinais, provocando erros e perda de sinal. Essa situação faz com que seja necessário que se façam retransmissões constantes, impactando no gasto energético do dispositivo. As prioridades alocadas para os dados sendo transmitidos são também muito relevantes neste caso específico.

Além da atenção com a questão da comunicação, é preciso também cuidar dos fatores que dizem respeito à segurança e privacidade dos dados, afinal, se tratam de informações pessoais e dependendo do caso, críticas para a saúde de alguém. Assim sendo, diversos recursos de segurança como criptografia, autenticidade e integridade devem ser implementadas em WBAN para garantir autenticação, integridade de dados, confidencialidade e disponibilidade dos dados (JARIWALA; JINWALA, 2020).

A autenticação é necessária para permitir que a WBAN valide os elementos da rede. A integridade de dados é composta por ferramentas para garantir integridade. Estas ferramentas também devem ser usadas para que, ao coletar as informações, o especialista, ou médico, tenha certeza de que não estão adulteradas e que são de fato do paciente informado. A confidencialidade é tratada por técnicas criptográficas. Estas técnicas garantem que as informações que trafegam pela rede até chegar ao destino sejam acessadas apenas por entidades autorizadas. A disponibilidade está relacionada às estratégias de como manter os recursos de rede sempre disponíveis às entidades. Dependendo da criticidade da aplicação em WBAN, a falta de informações pode custar a vida de uma pessoa.

As WBAN apresentam as seguintes vantagens:

- Permitem a mobilidade do paciente;

- Coletam de dados de forma ininterrupta; e

- Fazem o tratamento e tratam da precisão dos dados coletados.

Algumas da desvantagens da solução WBAN são: 
- A heterogeneidade dos dispositivos;

- O tempo reduzido da fonte de alimentação dos sensores corporais; e

- A barreira natural do corpo humano para a propagação de sinais sem fio.

A consolidação das redes corporais sem fio perpassa pela interoperabilidade entre seus componentes, ou seja, a necessidade de uma padronização. Além disso, são necessárias novas propostas para as seguintes questões:

- Métodos de implantação e garantia da qualidade de serviço (QoS) na comunicação de dados;

- Métodos de melhoria da confiabilidade dos dados; e

- Usabilidade.

O monitoramento remoto permitido pela redes corporais sem fio facilita e economiza em relação à dois componentes importantes: o tempo e os recursos envolvidos. Isso faz com que as WBAN se tornem uma tendência cada vez maior.

O monitoramento contínuo dos parâmetros fisiológicos através das WBAN independe do local onde o paciente esteja, o que possibilita, por exemplo, o acompanhamento de um idoso em casa, diminuindo a sua estadia no hospital e consequentemente as despesas do seu internamento. Na Figura 11, são ilustrados alguns tipos de sinais que podem ser mensurados por essa tecnologia.

Figura 11 - Exemplos de sinais fisiológicos monitoradas via WBAN.

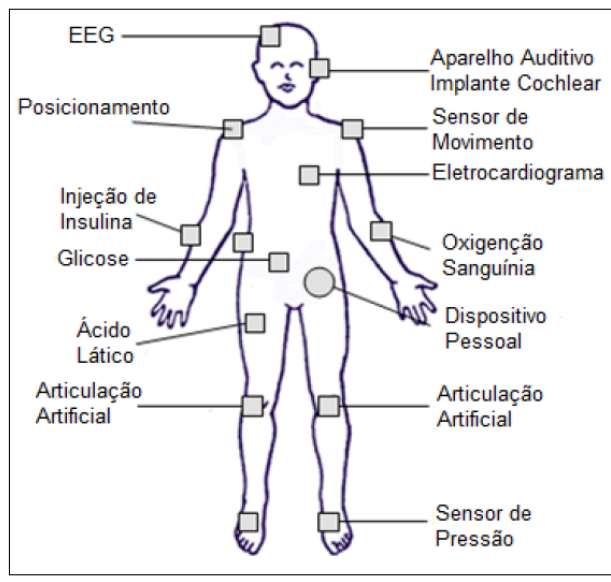

Fonte: OTTO, JOVANOV e MILENKOVIC (2006)

Com a crescente demanda nos serviços de cuidado da saúde, as WBAN têm se mostrado uma solução útil e promissora, reduzindo gastos e aumentando a qualidade de vida dos pacientes. 


\subsection{ESTRATÉGIA DE DISTRIBUIÇÃO DE DADOS PUBLISH/SUBSCRIBE (PUB/SUB)}

A estratégia de distribuição de dados Publish/Subscribe (Pub/Sub) consiste em um mecanismo que orquestra a comunicação entre produtores de informações, que publicam eventos no sistema, e consumidores de informações, inscritos em categorias específicas de tópicos no sistema (HUANG; GARCIA-MOLINA, 2004).

No modelo Pub/Sub, um consumidor expressa seu interesse em receber determinados dados dos produtores através da sua inscrição nos tópicos de interesse. Assim, quando um novo tópico é gerado e publicado no sistema Pub/Sub, o sistema coordena o envio das informações requisitadas por todas as inscrições registradas para receber aquele tipo de dado (tópico).

No contexto de uma aplicação médica, por exemplo, um consumidor pode expressar interesse em receber dados de temperatura de um determinado paciente, com a temperatura sendo o tópico específico requisitado (DEMERS et al., 2006).

Algumas das principais características e propriedades da estratégia de comunicação Pub/Sub são como segue (DEMERS et al., 2006):

- É um método de comunicação do tipo assíncrono, onde o produtor realiza a coleta de dados independentemente de solicitação do consumidor. Isso demonstra a necessidade de se ter um armazenamento temporário para que as informações sejam guardadas (DEMERS et al., 2006). No escopo do desenvolvimento do PSIoT-Health, objeto desta dissertação, essa é uma das tarefas do agregador.

- A comunicação Pub/Sub se assemelha à comunicação multicast por permitir que, com apenas uma operação, um produtor publique uma mesma informação para diversos consumidores (HUANG; GARCIA-MOLINA, 2004).

- O estilo de comunicação no Pub/Sub é anônima, ou seja, ela não exige que os elementos da comunicação se identifiquem. Por exemplo, se um consumidor deseja se inscrever em tópicos de um produtor, ele pode simplesmente indicar os tópicos, sem que haja a necessidade de se identificar ao produtor (HUANG; GARCIA-MOLINA, 2004).

- Nas situações onde existem requisitos de segurança, faz-se necessário acrescentar tais funcionalidades ao mecanismo de comunicação básico do Pub/Sub (HUANG; GARCIAMOLINA, 2004).

Essas características tornam o Pub/Sub, uma solução conveniente para atuar no contexto da IoT, lidando com uma quantidade grande de sensores em uma rede no estilo fog computing (HAPP et al., 2017).

Existem diferentes maneiras de implementação de sistemas Pub/Sub, conforme descrito em (NOUR et al., 2019). Os estilos variam em funçâo do estilo do tratamento da informação 
considerando principalmente a estratégia de implantação de sistemas baseados ou centrados na informação, ou ICN (Information-Centric Networks) (WU et al., 2019).

A discussão sobre ICN é fora do escopo desta dissertação e, considerando o objetivo geral desta que é a distribuição de dados médicos, pode-se então considerar que o modelo Pub/Sub pode ser entendido da seguinte forma:

- O modelo Pub/Sub é baseado em tópicos;

- Os produtores geram os tópicos, anunciam os mesmos (publicação ou divulgação) e os consumidores os consomem através de uma inscrição nos mesmos; e

- Para cada tópico anunciado e escolhido (com inscrição) pelos consumidores, são geradas as mensagens de envio dos tópicos para os consumidores.

A Figura 12 ilustra de forma resumida os elementos da estratégia de comunicação $\mathrm{Pub} /$ Sub e algumas de suas interações.

Figura 12 - Pub/Sub baseado em tópico.

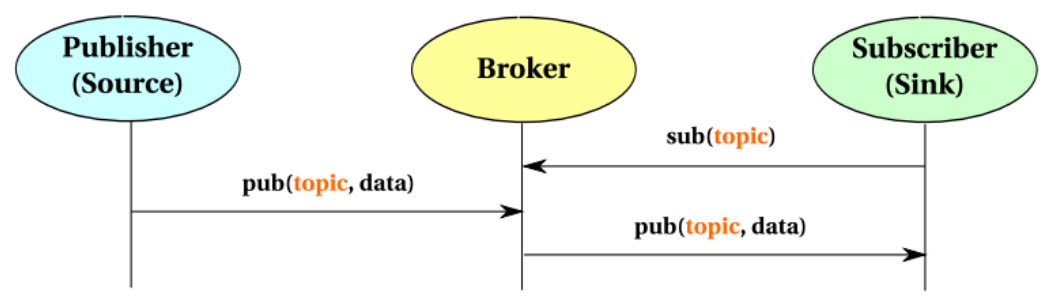

Fonte: UNKELER, TRUONG e STANFORD-CLARK (2008)

De forma genérica, o broker faz a ligação entre os consumidores e produtores.

- Os aplicativos consumidores interessados num determinado tipo de dado fazem suas inscrições para esse tópico;

- O dado do tópico (sensor ou outro) é coletado no broker; e

- O broker faz a publicação das informações para os consumidores e este se inscrevem nos tópicos; e

- Os dados do tópico são enviados para os consumidores com inscrição pelo broker.

Nesse contexto, o conjunto de produtores e consumidores podem mudar constantemente sem que os mesmos tenham ciência dessas mudanças. Essa característica é bastante interessante para uma rede de sensores, por exemplo, onde nós podem falhar e ser substituídos. Nesse caso, 
os aplicativos não precisam estar cientes das falhas e mudanças, eles apenas recebem seus dados quando os novos dispositivos começam a operar (DOMÍNGUEZ et al., 2013).

Os arcabouços suportando o estilo de comunicação Pub/Sub utilizam diversos protocolos de comunicação. Exemplos de protocolos utilizados em implementação de arcabouços $\mathrm{Pub} / \mathrm{Sub}$ incluem:

- MQTT (Message Queuing Telemetry Transport) (KANG et al., 2017); e

- ZigBee (PEIZHONG; IWAYEMI; ZHOU, 2011);

Segue um resumo do protocolo MQTT visando o entendimento de maneira geral de quais aspectos da comunicação Pub/Sub estes protocolos abordam e executam.

O MQTT é um protocolo Pub/Sub de troca de mensagens desenvolvido pela IBM (KANG et al., 2017). O protocolo MQTT possui dois elementos essenciais:

- O broker MQTT; e

- O consumidor MQTT.

A Figura 13 ilustra a operação do protocolo MQTT.

Figura 13 - Operação do protocolo MQTT.
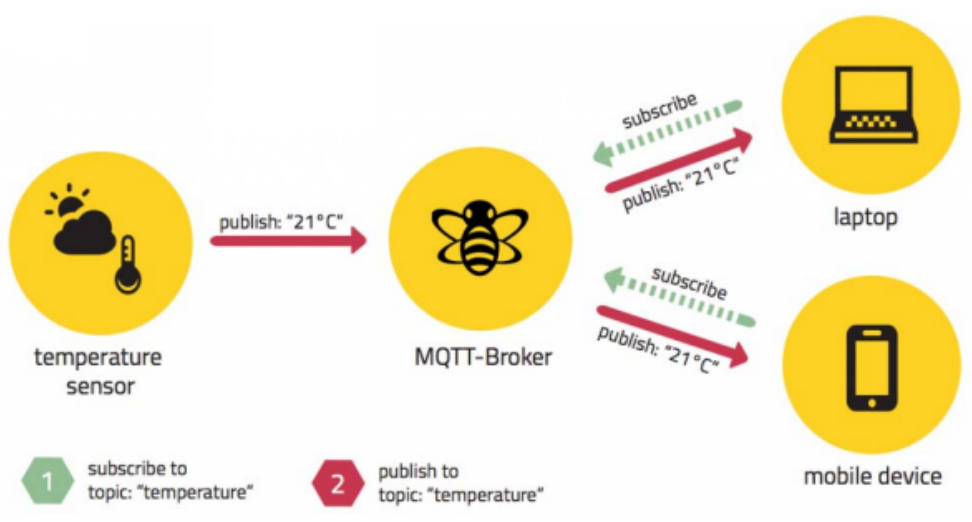

Fonte: KANG et al., 2017

As mensagens do MQTT permitem que os clientes se inscrevam em um ou mais tópicos do seu interesse ou cancelem suas inscrições, caso desejem (QUINCOZES; EMILIO; KAZIENKO, 2019). Na sua operação, o MQTT permite três níveis de qualidade de serviço (QoS):

- QoS com níveis 0,1 e 2; 
- Nível 0: as mensagens (dados consumidos) são enviadas sem direito a retransmissão e sem nenhuma confirmação de entrega;

- Nível 1: as mensagens (dados consumidos) podem ser retransmitidas diversas vezes e podem ser repetidas para o consumidor; e

- Nível 2: Garante que o consumidor receba a informação solicitada apenas uma vez.

\subsection{PUBLISH/SUBSCRIBE E FOG COMPUTING}

Uma outra questão de estratégia de implementação no contexto da internet das coisas diz respeito à maneira e à localização do armazenamento e do processamento dos dados IoT coletados.

Existem duas soluções clássicas de estilo de implementação que são tipicamente utilizadas:

- A computação e armazenamento de dados IoT de forma mais centralizada em centros de dados ou comutação em nuvem (cloud computing) (CHORBEV et al., 2017); e

- A computação e armazenamento de dados IoT de forma mais descentralizada, principalmente nas pontas (edge) da rede e próximas do produtor dos dados, denominada de fog computing ou edge computing (MUKHERJEE; SHU; WANG, 2018) (KRAEMER et al., 2017).

A estratégia fog computing com processamento e armazenamento dos dados IoT nas bordas (edge) é a adotada pelo PSIoT-Health, objeto desta dissertação.

De fato, é esperado que a produção e o consumo de dados IoT cresçam de forma significativa, então, é necessário que se estabeleça condições para que esse grande número de informações possa ser processado e armazenado.

Sabe-se que a grande maioria dos dispositivos utilizados no ambiente IoT terão energia escassa e capacidade computacional limitada, além disso, o tipo de comunicação estabelecida na maioria dos casos será de baixa potência e sujeito a atenuação.

Outra questão importante a frisar diz respeito às aplicações, que, nesse contexto podem ter requisitos fortes, necessitando, por exemplo, de resposta em tempo real e baixa latência, dentre outros (YANNUZZI et al., 2014).

Todas essas características tornam clara a necessidade de uma estrutura para que os dados IoT sejam processados e armazenados e a partir dessa demanda surge a questão de onde localizar os recursos necessários para que as aplicações funcionem adequadamente no ambiente IoT (YANNUZZI et al., 2014). 
Fog computing é um paradigma de computação distribuída que pode operar como uma camada intermediária entre os consumidores de dados ou uma estrutura tipo datacenter em nuvem e dispositivos IoT de maneira geral. Tipicamente, o fog computing é utilizado quando as aplicações IoT possuem limitações em relação aos recursos computacionais no ambiente próximo aos equipamentos IoT, principalmente sensores (MAHMUD; KOTAGIRI; BUYYA, 2018).

No caso específico do PSIoT-Health, a estratégia fog computing é realizada através de um conjunto de agregadores de dados IoT e uma infraestrutura de comunicação baseada em rede que distribui os dados consumidos pelas aplicações.

\subsection{CIDADES INTELIGENTES NO CONTEXTO DA ÁREA DE SAÚDE}

O termo cidades inteligentes, ou Smart City, conceitua o propósito de utilizar as tecnologias da informação e comunicação (TICs) para melhorar o desempenho e a qualidade dos serviços urbanos (SOLANAS et al., 2014) (BEZERRA; MARISTELA; MARTINS, 2015).

O termo cidade inteligente ganhou destaque quando o Fórum das Comunidades Inteligentes premiou a cidade de Singapura com o título de cidade inteligente do ano analisando cinco indicadores: difusão de banda larga, competências para desenvolver e manter uma força de trabalho qualificada, inclusão digital, inovação e empreendedorismo, marketing e assessoria jurídica (STRAPAZZON, 2009).

Considerada como uma questão de responsabilidade mundial, a saúde é uma das temáticas mais discutidas no contexto das cidades inteligentes. Padrões mundiais de assistência médica são considerados indicadores significativos de desenvolvimento e de qualidade de vida (HUSSAIN et al., 2015).

As cidades inteligentes utilizam os equipamentos da IoT, tipo sensores, para colher dados e informações sobre diversas variáveis no ambiente das cidades e centros urbanos. Exemplos de dados e informações capturados incluem a temperatura, umidade, concentração de alérgenos, poluição, condições de tráfego e assim por diante (SOLANAS et al., 2014). O objetivo é utilizar esses dados para identificar previamente possíveis problemas, otimizá-los ou resolvêlos (STRAPAZZON, 2009). No caso da área de saúde essa finalidade é ainda mais necessária, pois, um tratamento ou socorro no momento correto pode salvar uma vida.

No início dos anos 2000, as Plataformas de Registros Eletrônicos de Saúde (EHRS) e Registros de Saúde Pessoal (PHRs) surgiram como mais um resultado da união entre tecnologia e saúde e começaram a influenciar o governo em relação aos investimentos destinados a esse campo. A extração de dados desses registros históricos possibilitou que médicos detectassem condições comuns em subpopulações inteiras e compreendessem tendências (COOK et al., 2018). 
É esperado que os serviços de saúde baseados nas tecnologias da IoT reduzam custos públicos (COOK et al., 2018). Segundo prestadores de cuidados de saúde, a utilização de ferramentas inteligentes supera barreiras geográficas e temporais e, além disso, ajudam, por exemplo, a identificar corretamente o momento de reabastecer suprimentos para o funcionamento contínuo dos equipamentos (ISLAM et al., 2015).

As tendências em pesquisa e desenvolvimento de serviços para a área da saúde baseados em IoT incluem arcabouços suportando serviços de saúde, arquiteturas de rede adequadas para o tráfego de aplicações médicas, plataformas de desenvolvimento, novos serviços e aplicações, interoperabilidade, e segurança, dentre outros (ISLAM et al., 2015).

Além disso, dois fatores agregam para o impulsionamento da inserção de novas tecnologias aos serviços de saúde, o primeiro, é o fato de países estarem desenvolvendo políticas e diretrizes para impulsionar a tecnologia IoT na medicina; o segundo, é a crescente tendência em discutir os desafios práticos atuais para que as nossas cidades se tornem cidades inteligentes.

Considerando que, um dos objetivos das Smart Cities é melhorar a qualidade de vida dos cidadãos, temos a saúde como uma questão primordial e é nesta perspectiva que a solução PSIoT-Health desenvolvida nesta dissertação se enquadra. 


\section{ARCABOUÇO DE COMUNICAÇÃO DE DADOS IOT COM ESTRATÉGIA PU- BLISH/ SUBSCRIBE (PSIOT)}

O arcabouço de comunicação de dados IoT com estratégia Publish/Subscribe (PSIoT) é uma solução que permite o envio a recepção de dados entre produtores (Publishers) e consumidores (Consumers) em diversos domínios de aplicação. Uma descrição detalhada da arquitetura, princípios de concepção e operação do PSioT está disponível em Moraes (MORAES; MARTINS, 2019) (MORAES; REALE; MARTINS, 2018) (MORAES, 2018).

O PSIoT-Health desenvolvido nesta dissertação tem como base operacional e base de desenvolvimento o arcabouço PSIoT. O PSIoT-Health amplia e customiza a operação do PSIoT no contexto específico das aplicações médicas distribuídas que envolvem a coleta e distribuição de dados médicos.

Segue um detalhamento dos aspectos mais importantes da operação do PSIoT e que são relacionados ao desenvolvimento do PSIoT-Health.

\subsection{PSIOT - ASPECTOS BÁSICOS DA ARQUITETURA}

O arcabouço PSIoT foi desenvolvido para fazer o gerenciamento da transmissão através de uma rede de um grande volume de dados gerados pelo crescente número de dispositivos IoT em diversos domínios de aplicação. O PSIoT utiliza o paradigma Publicar/Subscrever ( $P u$ blish/Subscribe), comumente denominado de Pub/Sub (NOUR et al., 2019), para:

- Lidar com os recursos da rede (banda disponível) de maneira eficiente;

- Permitir uma comunicação de dados eficaz entre sistemas geradores e sistemas coletores de dados; e

- Suportar uma solução de comunicação largamente distribuída de produtores e consumidores de dados.

A Figura 14 ilustra a visão de utilização do arcabouço PSIoT onde diversos gateways IoT coletam dados que são distribuídos entre os consumidores de dados através de uma rede. Na solução PSIoT a rede de comunicação tem recursos limitados (banda nos enlaces) e que são compartilhados para a comunicação de dados entre produtores e consumidores. 
Figura 14 - Visão do Usuário do PSIoT.

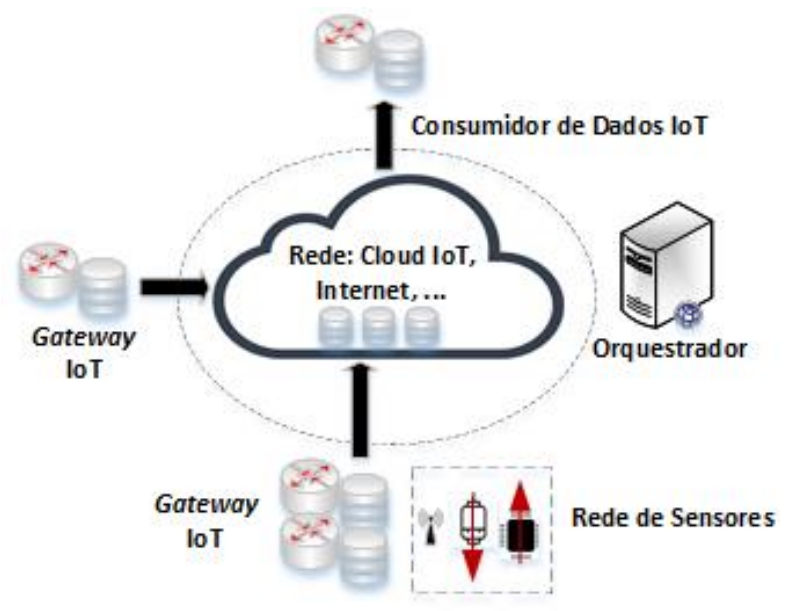

Fonte: (MORAES; REALE; MARTINS, 2018) - Figura adaptada pelo autor

Os componentes principais do arcabouço PSIoT são os seguintes (Figura 15):

- Orquestrador PSIoT;

- Gateways IoT;

- Produtores e consumidores de dados; e

- Rede de comunicação interconectando produtores e consumidores.

Figura 15 - Componentes principais do PSIoT.

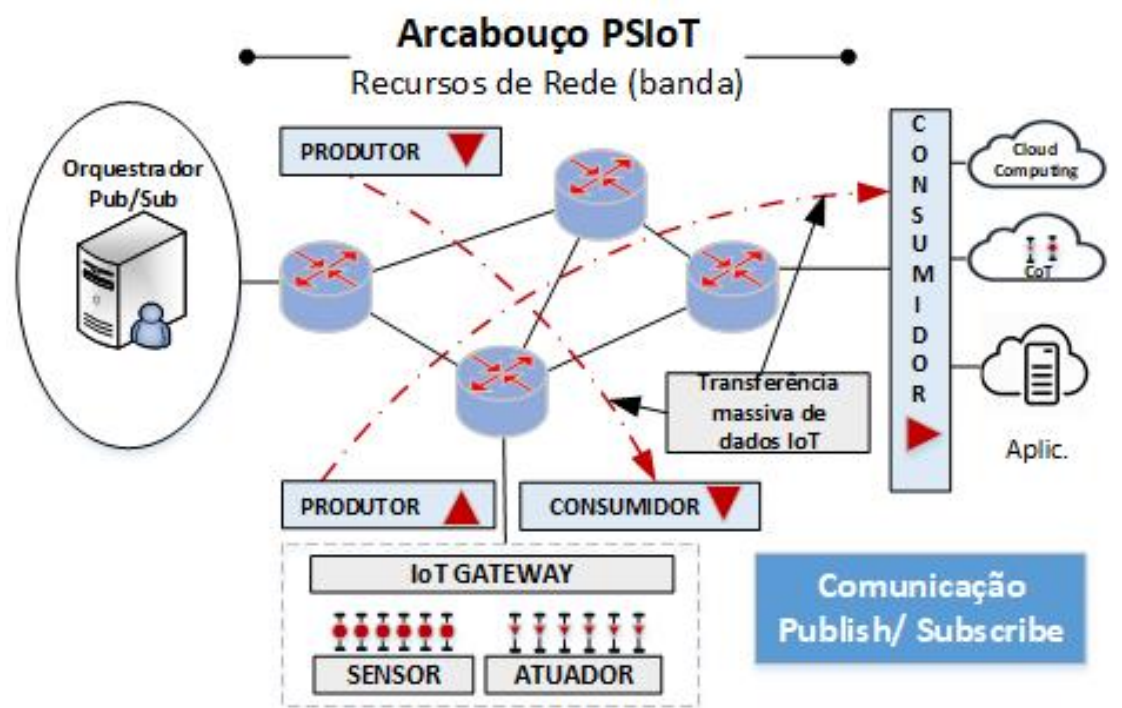

Fonte: (MORAES; MARTINS, 2019) 
O PSIoT gerencia o tráfego IoT entre produtores e consumidores controlando as filas de transmissão de dados (saída) dos gateways IoT na borda da rede. As funções específicas dos componentes internos do PSIoT são as como segue:

- Agregadores de dados: são gateways IoT tipo Fog (IoTGW-Ag), ou seja, são nós do tipo Fog que agem como agregadores de dados IoT e produtores Pub/Sub.

- Orquestrador: é um módulo de gerenciamento de tráfego IoT na borda da rede.

- Clientes Pub/Sub: podem ser aplicativos do usuário final ou programas de centros de cessação.

- Sensores: são os equipamentos que geram os dados a serem consumidos.

Os agregadores permitem o pré-processamento de dados juntamente com todos os demais benefícios relacionados a Fog computing enquanto habilita a modelagem e priorização de tráfego com base nas prioridades da transmissão de dados de IoT. A principal função dos agregadores de dados de IoT nas bordas da rede é permitir que o PSIoT tenha um conhecimento mais preciso sobre dados da IoT.

Além das funcionalidades citadas, esses nós também tem capacidade de assumir outros tipos de demandas relacionadas à IoT, como backup e armazenamento em cache por exemplo.

Orquestrador de tráfego: o orquestrador PSIoT é responsável por gerenciar o fluxo de tráfego de IoT dos agregadores da rede. Com o conhecimento de cada assinatura Pub/Sub dos IoTGWAg, bem como os níveis de QoS necessários para cada sub-tópico, o orquestrador define as taxas de transmissão de dados de IoT para cada agregador na rede com o objetivo de garantir o rendimento de assinaturas de QoS de nível mais alto.

O framework PSIoT conta com duas funcionalidades:

- Gerenciamento de recursos de link: para ajustar a largura de banda entre os switches da rede no percurso entre os agregadores e os consumidores; e

- Gerenciamento de QoS do tráfego IoT: para habilitar o controle de todos os produtores de dados da IoT nas filas dos agregadores.

O orquestrador PSIoT se baseia na sensibilidade ao tempo do tráfego de IoT para realizar a determinação dos níveis de QoS nos agregadores e a troca de mensagens entre o orquestrador (centralizado) e os demais componentes da infraestrutura. O gerenciamento das taxas de transmissão de agregadores é realizado para que os dados de IoT com prioridade mais alta tenham primazia em relação a carga de tráfego global da IoT na rede. 
O PSIoT pode ser inserido em qualquer infraestrutura de rede, incluindo a Internet, onde não há controle sobre os recursos de rede que estão sendo usados e além de introduzir um controle de QoS (apenas no nível de borda da rede), também executa uma estratégia de alocação de largura de banda de enlaces de rede baseados em SDN.

O desenvolvimento realizado por (MORAES; MARTINS, 2019) manteve o foco nos métodos de gerenciamento do tráfego gerado por dispositivos IoT e, para permitir no PSIoT a programação dos fluxos de IoT (heterogêneos) nos switches implementados na rede, foi utilizado um controlador SDN (Software-defined Networking).

Nesse cenário, uma estrutura Pub/Sub foi utilizada para permitir a transferência de dados da IoT entre produtores e consumidores e gerenciar os recursos da rede de forma eficiente, levando em consideração a QoS no nível da borda.

Dentro do ambiente apresentado no projeto PSIoT, o tráfego precisa percorrer dos sensores IoT para os agregadores e a partir desse momento, utilizar uma rede controlada. Esse trajeto dificulta o estabelecimento de uma hierarquia comum para as necessidades de QoS do tráfego IoT, por isso, (MORAES; MARTINS, 2019) optam por adaptar os requisitos de QoS de acordo com a capacidade dos recursos da rede e dos seus dispositivos locais.

Ao utilizar a SDN para gerenciar os recursos de enlace de rede e tomar decisões a cerca de roteamento, o PSIoT garante o gerenciamento de tráfego e QoS de IoT. Ou seja, garante a QoS gerenciando eficientemente a largura de banda de link entre os usuários da rede.

\subsection{PSIOT - MODELO DE TROCA DE MENSAGENS PUB/SUB E OPERAÇÃO}

Do ponto de vista dos seus usuários (produtores e consumidores de dados), a operação do PSIoT é baseada no paradigma Publish/Subscribe.

Em resumo, a operação de coleta ou troca de dados no PSIoT usando Pub/Sub é como segue:

- Os produtores geram os dados e divulgam para o orquestrador e para os usuários usando as mensagens Pub/Sub;

- Os consumidores requisitam os dados gerados pelos produtores usando Pub/Sub; e

- O orquestrador controla o fluxo de dados entre produtores e consumidores, segundo suas demandas e garantindo os limites de banda disponíveis nos enlaces da rede.

Essa comunicação é efetivamente realizada usando um modelo de mensagens $\mathrm{Pub} / \mathrm{Sub}$ descrito em Arruda (ARRUDA et al., 2020) e ilustrado na Figura 16. 
Figura 16 - Modelo de Mensagem Pub/Sub do PSIoT.

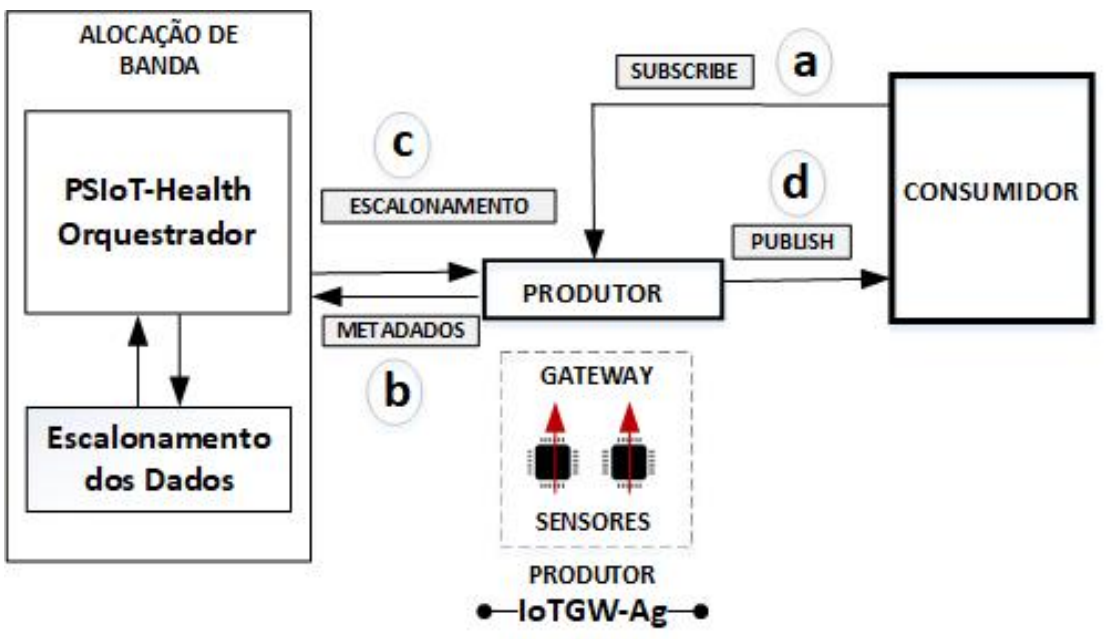

Fonte: (ARRUDA et al., 2020) - Adaptado pelo autor 


\section{ARCABOUÇO DE COMUNICAÇÃO DE DADOS COM ESTRATÉGIA PUBLISH/ SUBSCRIBE PARA APLICAÇÕES MÉDICAS (PSIOT-HEALTH)}

O arcabouço de comunicação PSIoT-Health tem como objetivo geral o transporte de dados médicos coletados de um paciente utilizando sensores especializados através de uma rede de computadores com recurso de banda limitados no contexto de uma cidade inteligente.

Do ponto de vista dos dados médicos coletados, a abordagem geral do PSIoT-Health utiliza o mecanismo de comunicação Pub/Sub para requisitar e receber os dados médicos dos pacientes de maneira geral (Figura 17).

Figura 17 - Visão do Usuário do PSIoT-Health.

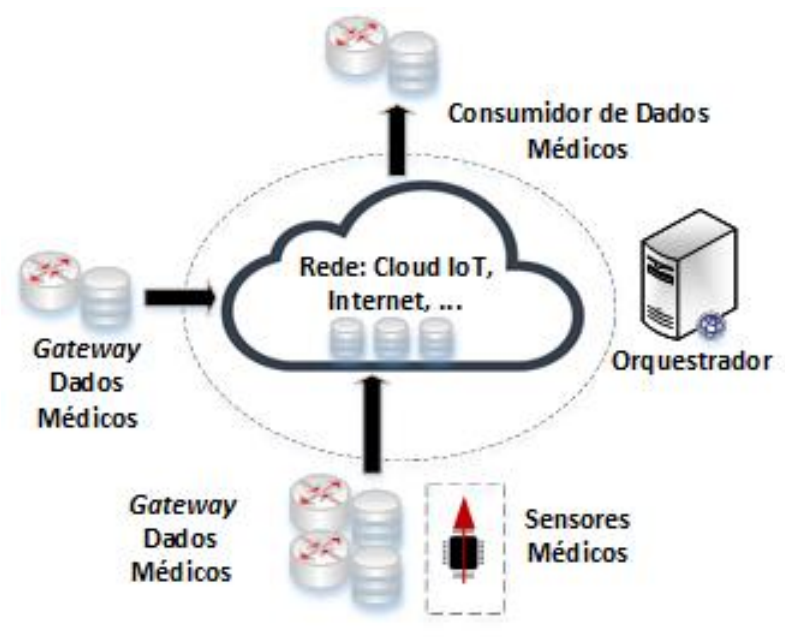

O fato do PSIoT-Health ter como alvo as cidades inteligentes significa que, numa implantação de campo, a solução tem vários gateways coletando dados de pacientes em diversos locais da cidade.

A arquitetura do arcabouço PSIoT-Health é composta por quatro componentes principais (Figura 18):

- Os sensores da aplicação médica alvo;

- Os gateways de aplicações médicas (gateway IoT);

- O orquestrador da comunicação de dados entre os produtores e os consumidores; e

- A rede de comunicação de dados com recursos de enlace limitados. 
Figura 18 - Arquitetura do PSIoT-Health.

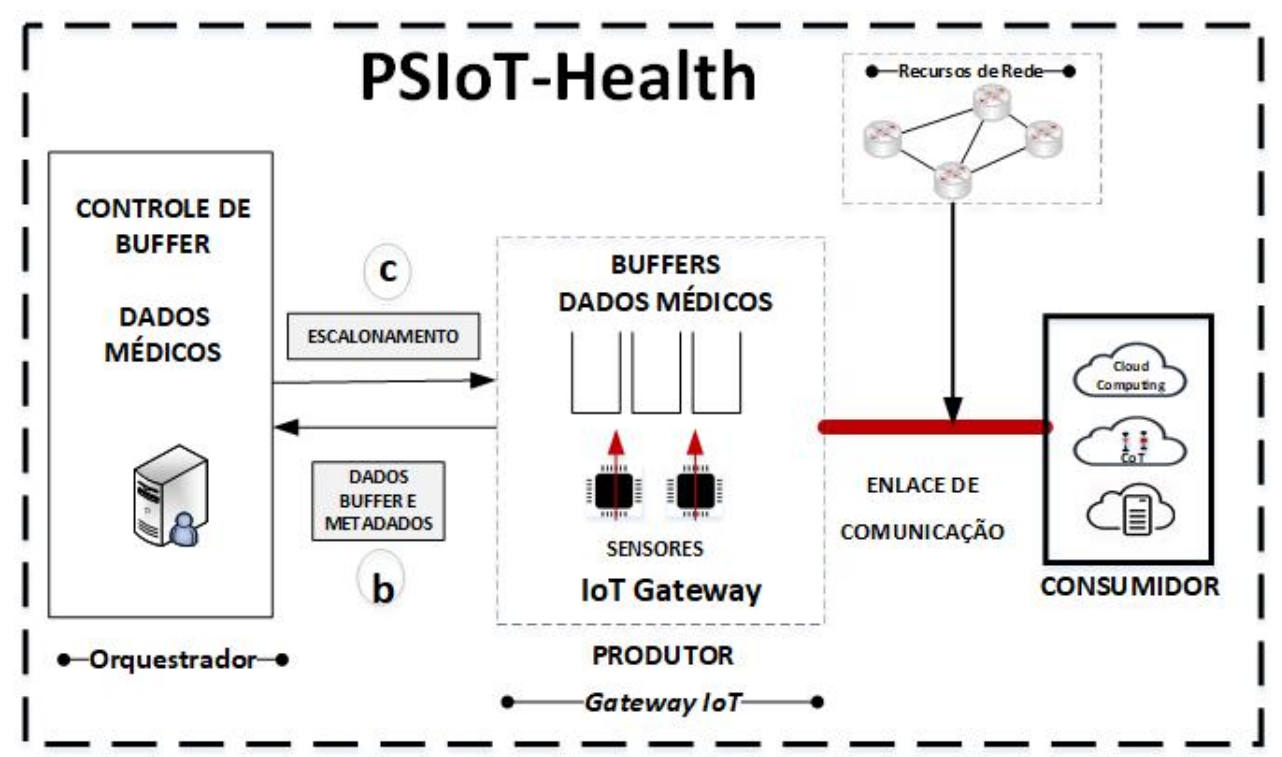

Os sensores de aplicação médica utilizados são sensores capazes de coletar o tipo de dado médico tratado na aplicação alvo do PSIoT-Health. No caso, os dados utilizados na aplicação alvo que serão objeto da prototipação e da simulação realizada para o PSIoT-Health são os seguintes:

- Dados tipo ABP (Ambulatory Blood Pressure);

- Dados de saturação do oxigênio (SpO2); e

- Dados de frequência cardíaca (tipo Pulse).

Os sensores utilizados num cenário típico do PSIoT-Health e na simulação implementada são pequenos, com a capacidade de energia, memória e processamento limitados. Por esse motivo, os dados coletados são enviados para o gateway IoT que tem uma capacidade computacional maior e que funciona como um agregador de dados coletados do paciente (KRAEMER et al., 2017).

Outra razão relevante para que a coleta de dados seja feita pelo gateway funcionando como um agregador é que esta opção de implementação permite o controle do fluxo de comunicação de dados através do controle das filas pelo orquestrador e, esta facilidade vai permitir o controle e a gerência da comunicação de dados entre produtores e consumidores. Dessa forma, o PSIoT-Health pode viabilizar soluções de transporte de dados médicos através de uma rede mantendo parâmetros de performance com, por exemplo, qualidade de serviço (QoS) e requisitos de tempo de entrega e validade de dados médicos. 


\subsection{GATEWAY E AGREGADOR DE DADOS MÉDICOS DO PSIOT-HEALTH}

O gateway IoT ou agregador dos dados médicos é outra componente do PSIoT-Health (Figura 18). De maneira geral, a técnica de agregação é utilizada em redes de sensores de maneira geral conforme Yan (YÁN; SCHAFFER, 2010) pois o agregamento permite um eventual pré-processmento dos dados brutos e o controle da transmissão desses pela rede.

No PSIoT-Health o agregador (gateway IoT) é controlado por um orquestrador localizado em algum ponto da rede para onde envia os seus metadados de estado das filas e tópicos Pub/Sub sendo tratados e de onde recebe a configuração (escalonamento) das taxas de transmissão de dados das suas filas de saída (Figura 18).

O fluxo de operação básica do agregador do PSIoT-Health associado a um orquestrador pode ser sumarizado da seguinte forma:

- O agregador coleta os dados médicos dos sensores para os tópicos Pub/Sub configurados (ABP, SpO2 e pulse para efeito da prototipação e simulação do PSIoT-Health);

- O agregador recebe inscrições dos consumidores para os seus tópicos Pub/Sub de interesse através do mecanismo Pub/Sub;

- O agregador envia para o orquestrador os metadados contendo informações sobre consumidores inscritos e tópicos Pub/Sub solicitados;

- O agregador também envia para o orquestrador os metadados contendo informações sobre os requisitos de tempo dos tópicos solicitados pelos consumidores;

- O agregador recebe do orquestrador as informações de escalonamento da transmissão dos dados dos tópicos de publicação solicitados; e

- O agregador publica (distribui) os dados referentes aos tópicos solicitados conforme os requisitos de tempo definidos pelos consumidores e utilizando uma banda de passagem calculada pelo orquestrador.

Segue uma descrição da operação do orquestrador em conformidade com a operação básica descrita para o PSIoT-Health.

\subsection{ORQUESTRADOR}

O orquestrador do PSIoT-Health é um componente chave da operação da distribuição dos dados da aplicação médica através de uma rede, por exemplo, numa cidade inteligente, pois trata do gerenciamento das filas dos agregadores existentes na rede. $\mathrm{O}$ orquestrador implementa as seguintes funcionalidades: 
- Gerenciamento dinâmico das filas de saída dos agregadores; e

- Cálculo dinâmico da largura de banda associada às filas dos agregadores na rede.

O gerenciamento das filas é realizado através do mecanismo Pub/Sub de troca de mensagens conforme ilustrado na Figura 16. Ele basicamente permite que o orquestrador altere as configurações de banda associada às filas com o processamento e operação do PSIoT-Health recebendo solicitações de tópicos pelos consumidores re informando o orquestrador destas solicitações.

O cálculo dinâmico da largura de banda associada às filas dos agregadores é uma das contribuição deste trabalho de dissertação no contexto do arcabouço Pub/Sub sendo aplicado para uma aplicação médica no contexto de uma cidade inteligente. Um novo cálculo de banda associada à cada fila é sempre feito quando a configuração de consumidores de filas é alterada por uma nova solicitação.

\subsection{O CONSUMIDOR PUB/SUB}

O consumidor Pub/Sub do PSIoT-Health é efetivamente um cliente que solicita dados médicos. A solicitação do cliente é realizada no PSIoT-Health através do mecanismo de mensagens Pub/Sub e comporta os seguintes elementos:

- O tópico Pub/Sub que corresponde ao tipo do dado desejado;

- O agregador responsável pela coleta de dados do tópico solicitado; e

- O requisito de tempo desejado pelo consumidor para o recebimento dos dados referentes ao tópico solicitado.

\subsection{PSIOT-HEALTH - ORQUESTRADOR E AGREGADOR PARA APLICAÇÕES MÉDI- CAS}

O PSIoT-Health utiliza efetivamente os elementos do arcabouço PSIoT e, assim sendo, cumpre identificar quais elementos e aspectos do PSIoT são modificado de forma a que o arcabouço contenha os elementos de implantação que permitem gerenciar um fluxo de dados Pub/Sub no contexto de uma aplicação médica visando o cenário de uma cidade inteligente.

Do ponto de vista da operação do arcabouço, o PSIoT-Health contempla os seguintes desenvolvimentos adicionais e específicos:

- Um estilo de utilização de mensagens Pub/Sub segundo as características e requisitos das aplicações médicas; 
- Um orquestrador que opera segundo um algoritmo de alocação de banda customizado para as aplicações médicas; e

- Um agregador cujas filas são controladas pelo orquestrador e que coleta dados dos sensores, aloca os mesmos em filas, gerencia as mesmas segundo as inscrições dos consumidores e encaminha os dados médicos (pacotes) em consonância com os requisitos das aplicações médicas.

Outro aspecto a considerar em relação à operação básica do PSIoT-Health é que este faz uso do mecanismo Pub/Sub tal qual e não houve investimento na sua modificação ou alteração na medida em que este é um mecanismo geral que pode ser aplicado tal qual no contexto de uma aplicação médica.

Assim sendo, segue uma descrição das implementações do orquestrador e do agregador do PSIoT-Health que customizam a operação do arcabouço Pub/Sub no contexto das aplicações médicas.

\subsection{O ORQUESTRADOR DO PSIOT-HEALTH}

O orquestrador do PSIoT-Health tem como função básica o cálculo da largura de banda alocada dinamicamente para cada fila do agregador sendo controlado (Figura 18).

O algorítimo 1 (Algoritmo de Alocação de Banda por Fila) calcula a banda a ser alocada para cada fila do agregador. $\mathrm{O}$ orquestrador recebe do agregador os metadados correspondentes ao estado de suas filas através de mensagem Pub/Sub usando a mesma rede de comunicação existente para o envio dos dados médicos. Os dados de entrada do algoritmo 1 são os seguintes:

- Tópico(s) Pub/Sub inscritos por consumidores que equivale à(s) fila(s) de saída correspondente(s); e

- Requisito de tempo do(s) tópico(s) Pub/Sub.

Os dados e metadados de entrada do algoritmo 1 são obtidos através da troca de mensagens Pub/Sub e o resultado do cálculo da banda a ser alocada para as filas de saída do agregador é passada também através de mensagens Pub/Sub (Figura 16). 


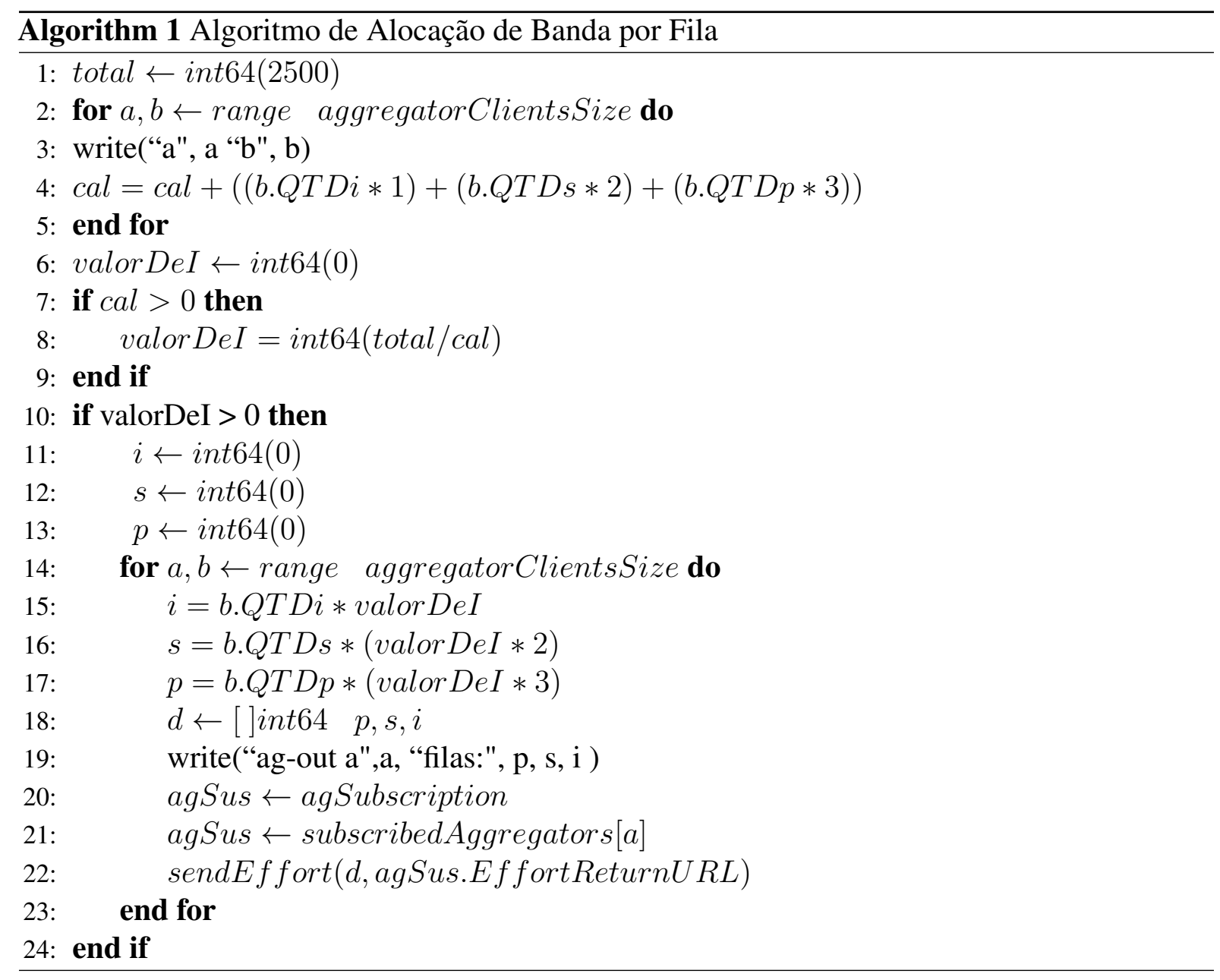

O cálculo da banda a ser alocada por fila feito pelo algoritmo 1 parte da banda total disponível para o enlace de comunicação entre o agregador e o consumidor ou consumidores localizados . Esse é um parâmetro de configuração do agregador. Assume-se nesta implementação que existe um mecanismo de comunicação de dados entre o agregador e o(s) consumidores num determinado ponto da rede com banda configurável.

O algoritmo varre inicialmente as inscrições por fila e coleta os seus parâmetros. As variáveis de entrada consideradas pelo algoritmo são então as seguintes:

- Quantidade total de banda;

- Quantidade de inscritos em cada fila; e

- A prioridade de cada fila.

De posse dessas informações, o programa realiza o calculo do valor base de banda destinado às filas de dados para a configuração de parâmetros coletada.

A prioridade de cada fila é determinada empiricamente nesta implementação como uma função dos tempos de entrega associados ao agregador para cada fila. Em resumo, o agrega- 
dor vai esvaziar as filas tentando manter os tempos de entrega solicitados pelos consumidores embora, nesta implementação, não existe garantia de tempo de entrega.

Assim sendo, faz-se necessário definir um padrão de tempo de reposta associado à cada fila de forma a permitir a determinação de suas respectivas prioridades. No contexto da prototipação realizada para o PSIoT-Health e testes de verificação tem-se uma relação de tempo de resposta associado às filas como segue:

- $T 2_{F 2}=2 * T 3_{F 3} ; \mathrm{e}$

- $T 1_{F 1}=3 * T 3_{F 3}$.

Onde:

- T1,T2 e T3 são os tempo de entrega da informação médica solicitados pelos consumidores; e

- $T 1>T 2>T 3$.

Do ponto de vista da implantação do agregador, existem então três filas com a relação de tempo de entrega conforme determinado, onde:

- Fila 1: é a fila denominada insensível com peso 1;

- Fila 2: é a fila denominada sensível com peso 2; e

- Fila 3: é a fila denominada prioritária com peso 3.

O fator de peso ou de prioridade entre as filas é uma variável que pode ser alterada. Este aspecto que impacta na operação do agregador não foi avaliado no escopo desta dissertação.

O cálculo da banda por fila usa a equação abaixo que, basicamente, computa a carga de pedidos dos diferentes tipos de dados nas fila considerando os seus respectivos pesos que refletem os tempo de resposta e prioridades associadas.

$$
\begin{aligned}
& c a l=c a l+((b . Q T D i * 1)+(b . Q T D s * 2)+(b . Q T D p * 3)) \\
& \text { valorDeI }=(\text { total } / \mathrm{cal})
\end{aligned}
$$

Onde:

- b.QTD $i$ representa a quantidade de inscritos na fila de dados insensíveis;

- b.QTDs representa a quantidade de inscritos na fila de dados sensíveis; e

- b.QT Dip representa a quantidade de inscritos na fila de dados prioritários; 
- total representa a quantidade de banda disponível; e

- valorDeI representa o valor de banda base (tipo uma fatia) após a distribuição entre todos os consumidores.

O resultado dessas operações é o valor base da quantidade de banda a ser alocada por consumidor com a normalização de seus pesos e prioridades.

O valor da banda que será atribuída às três filas do agregador é então calculado como segue:

- Banda da fila $1->i=b . Q T D i *$ valor DeI

- Banda da fila $2->s=b . Q T D s *($ valor DeI $* 2)$

- Banda da fila $3->p=b . Q T D p *($ valor $D e I * 3)$

Ao calcular os valores de banda para cada fila, o orquestrador os envia para o agregador que realizará o envio do conteúdo de cada fila respeitando esses valores como taxas de transferência.

O cálculo da alocação de banda por fila é realizado e as filas do agregador são reconfiguradas em relação à banda de despacho de pacotes sempre que uma das seguintes condições acontece:

- A banda do enlace é alterada;

- A quantidade de consumidores é alterada em quaisquer das filas; e

- O requisito de tempo de um dados solicitado pelo consumidor é alterado, pois implica na alteração da fila de hospedagem do dado.

Para efeito de simplificação, assumiu-se nesta implementação protótipo que os pacotes transportando os dados médicos têm um tamanho fixo. A utilização de pacotes de tamanho variável implica num ajuste do cálculo prévio de forma que considere o volume de dados por pacote com um outro parâmetro utilizado para a distribuição da banda do enlace entre as filas.

\subsection{O AGREGADOR DO PSIOT-HEALTH}

A operação do PSIoT-Health no contexto das aplicações médicas necessita de uma implementação customizada do agregador de forma que este possa levar em conta os requisitos e aspectos específicos da transferência de dados médicos.

O agregador do PSIoT-Health tem dois aspectos específicos que devem ser customizados visando a sua operação no contexto de uma aplicação médica: 
- A manipulação de filas no agregador; e

- O escalonamento de pacotes.

Estes dois aspectos específicos são tratados pelos seguintes algoritmos:

- O Algorítimo de Manipulação de Filas (Algoritmo 2); e

- O Algoritmo de Encaminhamento de Pacotes (Algoritmo 3).

O algoritmo de manipulação de filas tem como objetivo alocar os dados provenientes dos sensores nas filas dos agregadores. A alocação de dados provenientes dos sensores nas filas do agregador é feita, em resumo, da seguinte forma:

- O dado é lido do sensor;

- O agregador verifica qual a demanda, se existente, de consumidor para o dado; e

- Se existe consumidor, o dado é colocado na fila adequada.

A periodicidade de leitura dos dados nos sensores é configurada no agregador e assumese que nunca é superior ao tempo mínimo de requisição do dado solicitado pelo consumidor. Ou seja, se no caso mais crítico um dado médico é solicitado pelo consumidor a cada 500 milisegundos, o agregador vai ler este dado no sensor segundo este parâmetro ou com um intervalo de tempo inferior.

De posse do dado médico amostrado no sensor, o agregador (algoritmo 2) varre as inscrições e verifica os consumidores que o solicitaram e identifica o intervalo de tempo requisitado para o envio do dado. O agregador aloca então o dado amostrado na(s) fila(s) correspondente(s). Pode ocorrer que um mesmo tipo de dado possa ser alocado em uma ou mais filas, dependendo das solicitações dos consumidores e seus requisitos de tempo associados.

As requisições de tempo de entrega dos dados médicos solicitadas pelos consumidores são mapeadas nas três opções de fila que,na prática, correspondem a três tempos de entrega distintos com maior ou menor prioridade. 


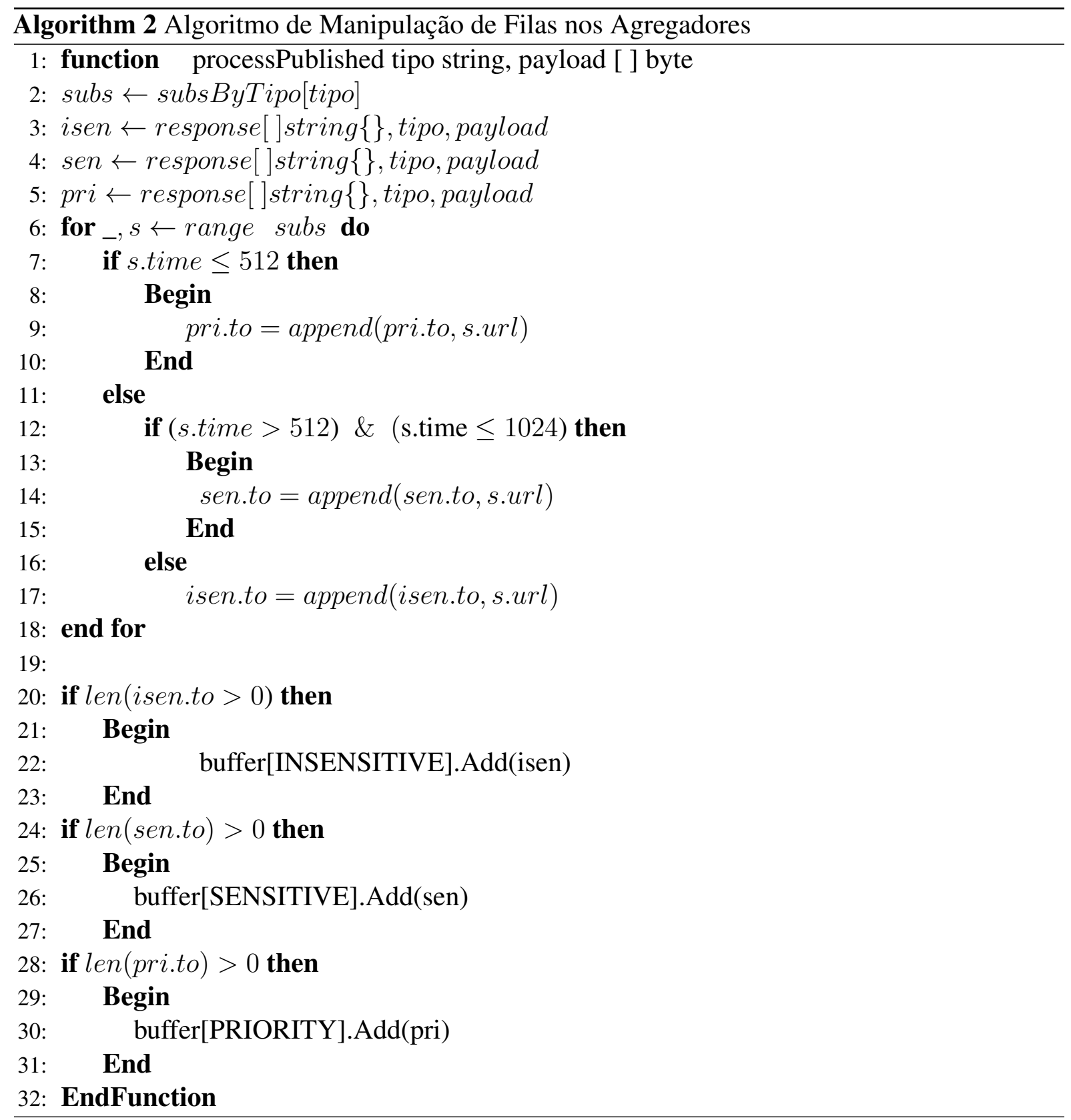

O algoritmo de encaminhamento de pacotes (Algoritmo 3) tem por objetivo realizar o despacho dos dados médicos armazenados nas filas do agregador para os consumidores inscritos.

O algoritmo de encaminhamento ou despacho de pacotes utiliza os seguintes parâmetros de entrada:

- Identificação da(s) fila(s) para o despacho; e

- Prioridade e alocação de tempo para execução do despachos na(s) fila(s).

O algoritmo executa a função time.Tick, (nativa do Golang), que realiza a execução de uma tarefa repetidamente em um certo intervalo de tempo que nesse caso, é o intervalo de tempo 
relacionado à prioridade da fila.

O dado médico enviado para o consumidor é sempre o dado mais recentemente amostrado e o processo de despacho dos pacotes é executado até que uma das seguintes condições ocorra:

- $\mathrm{O}(\mathrm{s})$ dado(s) foi(ram) enviado(s) para todos os consumidores inscritos na fila;

- A fila ficou vazia; ou

- O tempo de execução do despacho na fila expirou.

O despacho atende as filas do agregador na ordem da fila mais prioritária para a fila menos prioritária e considera o envio de dados para os consumidores segundo sua ordem de inscrição (disciplina FIFO - First-In First-Out) apenas para efeito de consistência no atendimento aos consumidores.

Uma outra informação geral relevante no contexto do desempenho da implementação do agregador é que os algoritmos de manipulação das filas e de despacho de pacotes são executados como threads no agregador. De maneira geral, isso sinaliza que existe um limite para a operação eficiente do agregador sem perda de dados médicos.

Na realidade, o desempenho do agregador depende do seguinte conjunto de parâmetros de operação considerando um número fixo de filas:

- Número máximo de consumidores;

- Tempos de resposta solicitados; e

- Número de tipos de dados médicos distribuídos pelo agregador.

O fato é que se o número de consumidores aumentar muito, ou o tempo de coleta e distribuição dos dados for configurado com valores muito baixos (mais críticos em termos de tempo de resposta), ou a quantidade de tipos de dados aumentar, ou uma combinação deste fatores ocorrer, podemos ter uma situação onde a própria operação do agregador implica em perda de dados. Isso mesmo que o enlace de dados tenha banda suficiente para transmissão de todos os dados nos tempos requeridos. Esse aspecto de avaliação da operação não foi considerado nesta implementação do PSIoT-Health e será objeto de trabalho futuro. 


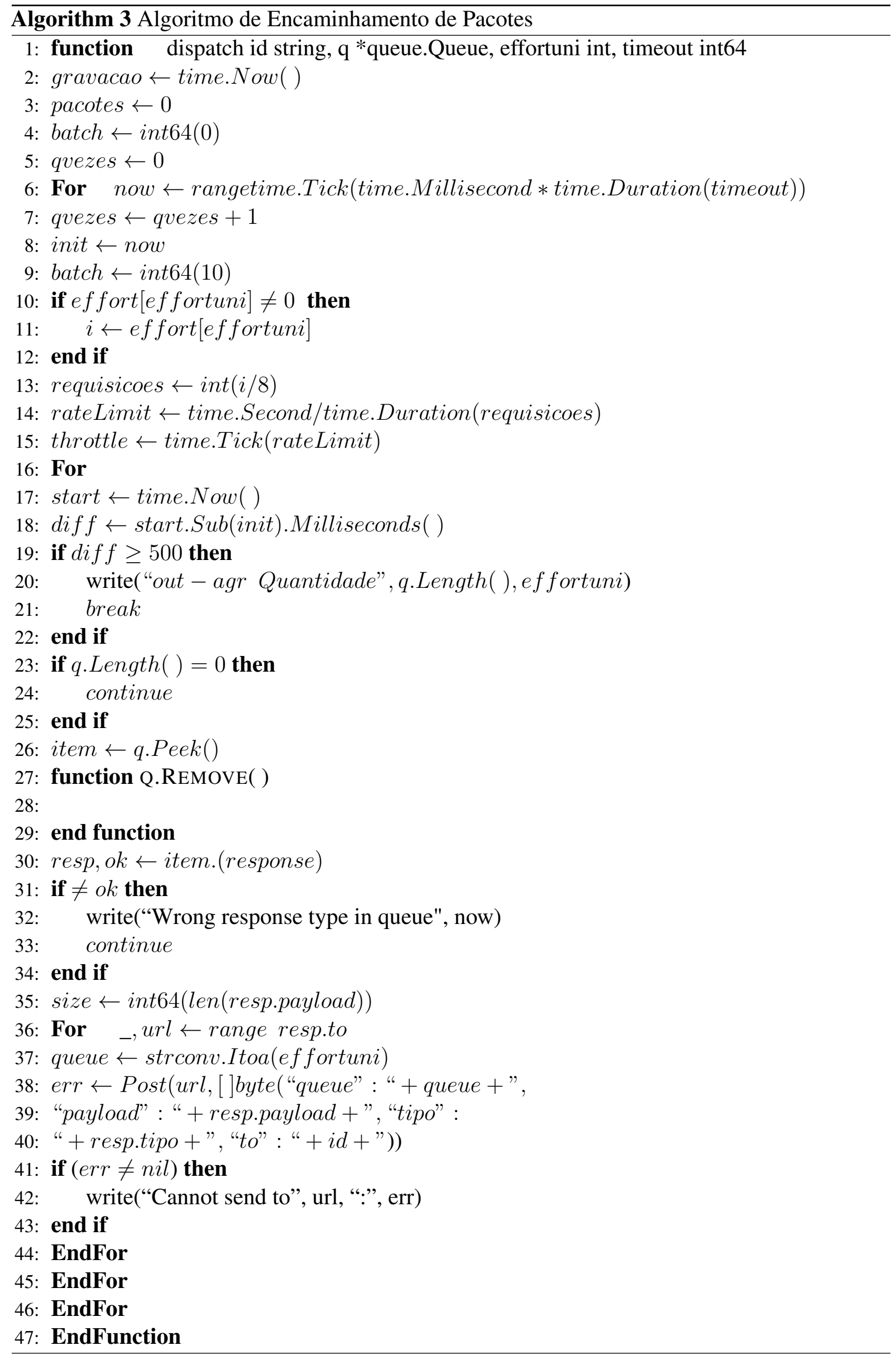




\subsection{DESENVOLVIMENTO DO CÓDIGO DO PSIOT-HEALTH}

O desenvolvimento do PSIoT-Health envolveu os seguintes novos módulos, componentes e adaptações de código em relação ao arcabouço PSIoT, base operacional do desenvolvimento:

- O desenvolvimento do módulo orquestrador;

- O desenvolvimento do módulo agregador; e

- O desenvolvimento e adaptação das interfaces de acesso ao arcabouço.

A adaptação da interface de acesso ao arcabouço visa permitir a interação da aplicação médica com o arcabouço considerando um novo conjunto de dados com suas características específicas. Esta adaptação é particularmente importante nos testes de operação do PSIoT-Health. O código desenvolvido para o PSIoT-Health tem os seguintes dados gerais;

- Linguagem de programação: Linguagem GO e Golang (GOLANG.ORG, 2020);

- Ambiente de desenvolvimento: VisualCode; e

- Percentual aproximado de alterações em relação ao código do PSIoT: 50\%. 


\section{PROVA DE CONCEITOS - AMBIENTE DE TESTE E RESULTADOS}

Um protótipo do PSIoT-Health foi desenvolvido com a implementação de um orquestrador e um agregador de dados orientados para as aplicações médicas.

Como fase seguinte do desenvolvimento foram realizados um conjunto de testes de operação do PSIoT-Health que visam:

- Testar a funcionalidade do algoritmo de orquestração de banda do PSIoT-Health; e

- Verificar o nível de eficiência do comportamento do agregador.

O teste de funcionalidade verifica o comportamento do orquestrador através do cálculo do valor da banda de cada fila do agregador para diferentes cenários de disponibilidade de banda total e de demanda de transferência de dados pelos consumidores.

A verificação da operação é feita com o envio de dados para diferentes consumidores, com filas de diferentes prioridades e com diferentes critérios de tempo de entrega dos dados.

\subsection{O AMBIENTE DE TESTE DO PSIOT-HEALTH}

O ambiente de testes que simula a operação do PSIoT-Health coletando dados de uma aplicação médica e enviando os mesmo para os seus consumidores é configurado como segue (Figura 19):

- Oito clientes consumidores de dados, inscritos em três tópicos distintos $\left(C_{i}\right)$;

- um agregador coletando dados $\left(A G_{i}\right)$;

- Três tipos de dados médicos coletados por agregador (ABP, SPO2 e Pulse);

- Cenários de rodadas de teste: 3 cenários com bandas de enlaces distintas;

- Duração da rodada de testes: 18 Minutos 
Figura 19 - Ambiente de teste do PSIoT-Health.

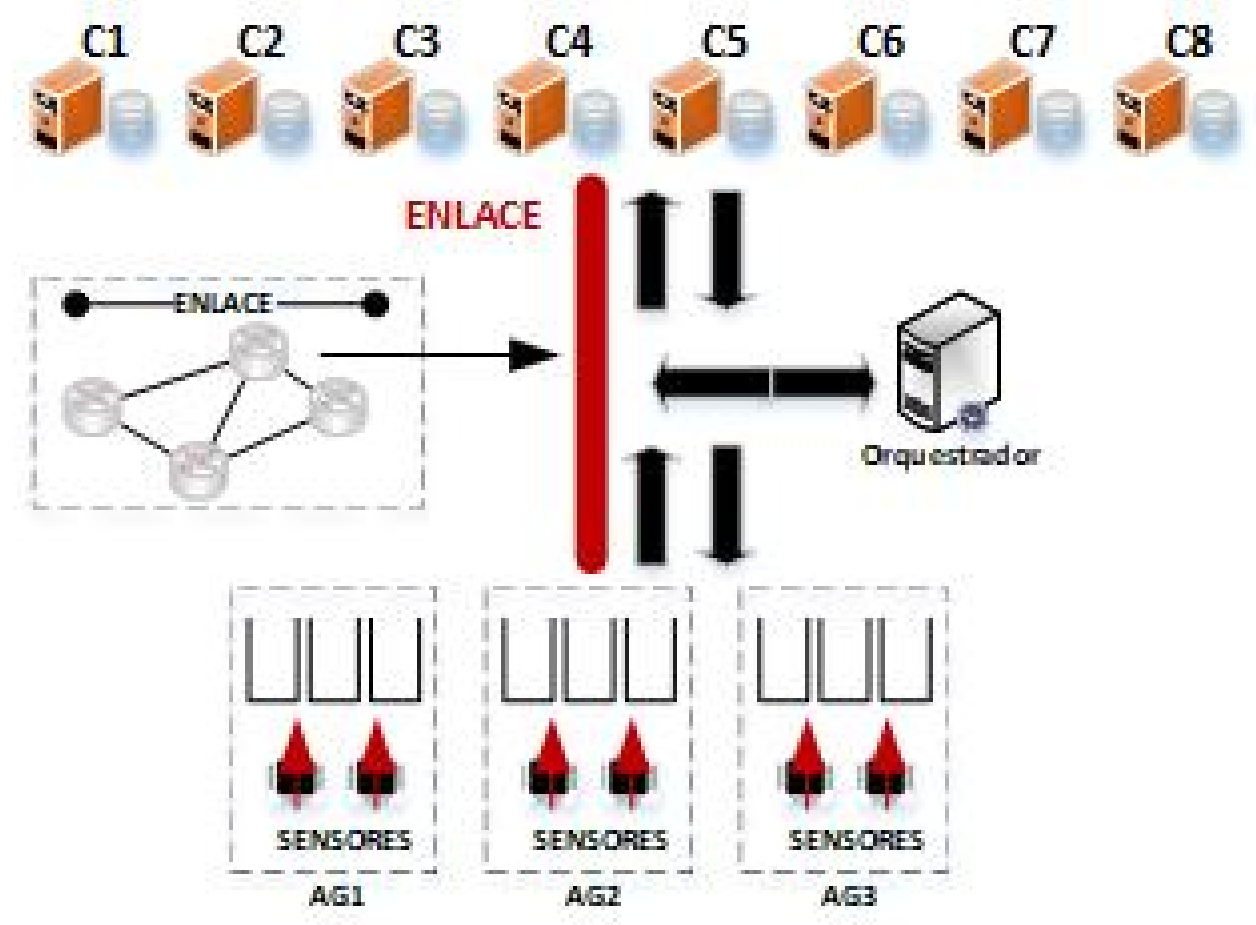

O mecanismo de transferência dos dados médicos do PSIoT-Health é acionado pelo usuário utilizando três parâmetros como segue:

- O endereço do agregador;

- O tempo de intervalo em que deseja receber os dados; e

- O tipo de dado que deseja receber.

O agregador é configurado com três filas de saída com as seguintes características:

- Fila de dados prioritários;

- Fila de dados sensíveis: e

- Fila de dados insensíveis.

A fila sendo prioritária, sensível ou insensível ao retardo indica o seu nível de prioridade de transmissão dos dados.

Em relação à rede suportando o consumo e a a distribuição dos dados entre o agregador e os consumidores:

- Existe um único enlace ou canal de comunicação, por exemplo tipo LSP (Label Switched Path), com banda configurável entre os agregadores e os consumidores; e 
- Todos os consumidores utilizam o mesmo enlace;

As inscrições dos clientes consumidores são ilustradas na Figura 20 onde:

- A fila 0 recebeu 9 subscrições;

- A fila 1 recebeu 9 subscrições;

- A fila 2 recebeu 6 subscrições;

Figura 20 - Inscrições dos Consumidores Pub/Sub.

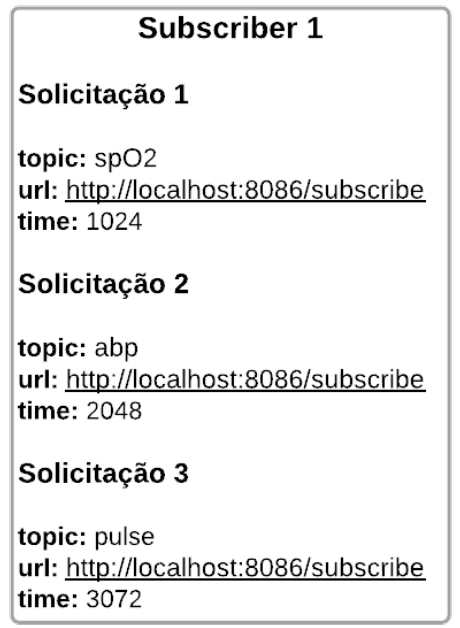

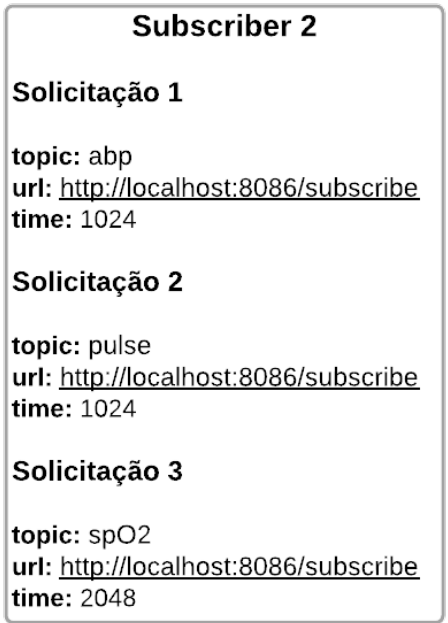

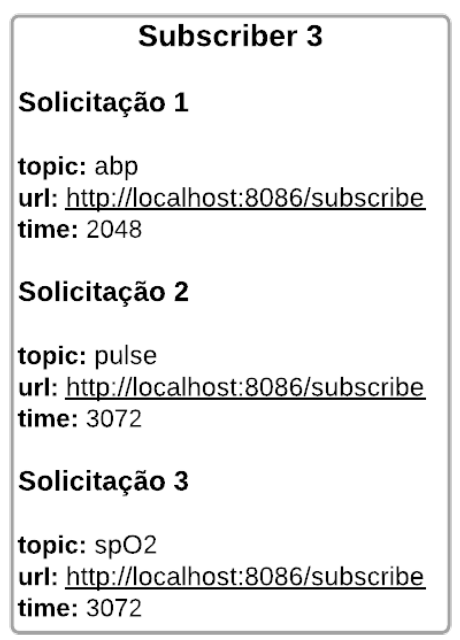

Subscriber 4

Solicitação 1

topic: abp

url: http://localhost:8086/subscribe

time: 1024

Solicitação 2

topic: pulse

url: http://localhost:8086/subscribe

time: 1024

Solicitação 3

topic: $\mathrm{spO} 2$

url: http://localhost:8086/subscribe

time: 1024 


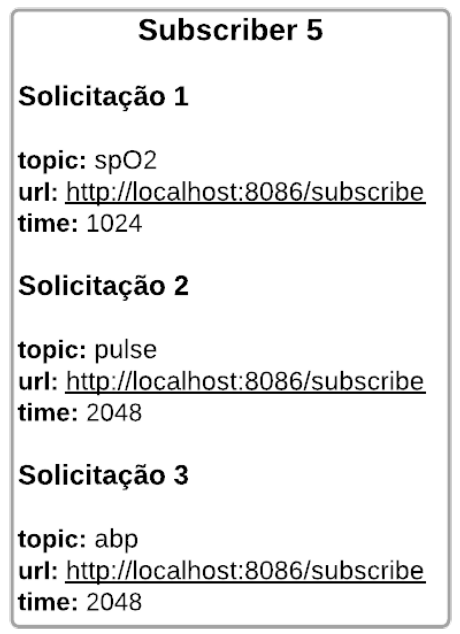

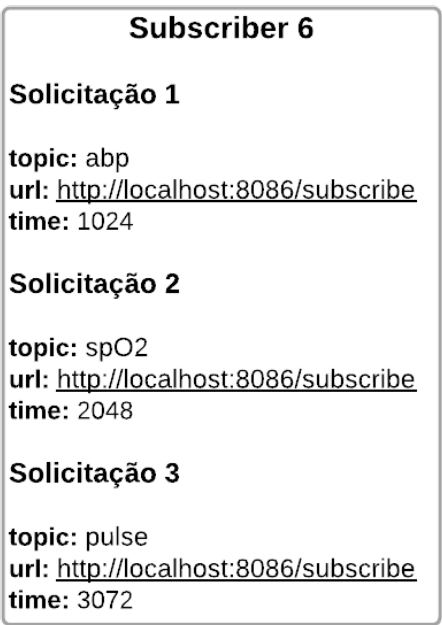

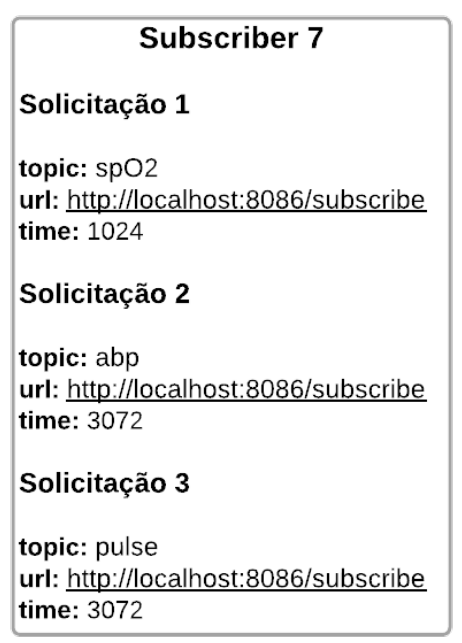

\begin{tabular}{l}
\multicolumn{1}{c|}{ Subscriber 8} \\
Solicitação 1 \\
topic: abp \\
url: http://localhost:8086/subscribe \\
time: 2048 \\
Solicitação 2 \\
topic: spO2 \\
url: http://localhost:8086/subscribe \\
time: 2048 \\
Solicitação 3 \\
topic: pulse \\
url: http://localhost:8086/subscribe \\
time: 2048
\end{tabular}

As inscrições são feitas em três rodadas de teste, com cada rodada tendo uma quantidade diferente de banda total disponível na rede conforme a Tabela 1. Os valores de banda são relativamente baixos de forma a situar o teste de operação de forma próxima à uma realidade suportada pela maioria das redes, inclusive a Internet. Numa situação de implantação do PSIoT-Health em campo, assume-se que existe uma facilidade na rede de garantia da banda configurada para o agregador.

Tabela 1 - Banda do enlace disponível para o agregador.

\begin{tabular}{rlll}
\hline Banda total & $5 \mathrm{kbps}($ Cenário 1) & 10kbps (Cenário 2) & 20kbps (Cenário 3) \\
\hline Fila prioritária & $2.647 \mathrm{kbps}$ & $5.294 \mathrm{kbps}$ & $10,59 \mathrm{kbps}$ \\
Fila sensível & $1.765 \mathrm{kbps}$ & $3.53 \mathrm{kbps}$ & $7,059 \mathrm{kbps}$ \\
Fila insensível & $0.5882 \mathrm{kbps}$ & $1,177 \mathrm{kbps}$ & $2,35 \mathrm{kbps}$ \\
\hline
\end{tabular}

Os dados médicos utilizados nos testes de operação do PSIoT-Health são oriundos de uma base dados com dados armazenados de pacientes em função da não disponibilidade de 
sensores e de pessoas que pudessem efetuar um teste operacional. A base de dados médicos utilizados contém dados amostrados de campo.

A base de dados médicos utilizada nos testes de operação do PSIoT-Health é a seguinte:

- MIMIC (Medical Information Mart for Intensive Care) (MOODY; MARK, 1996).

A base de dados MIMIC conta com cerca de 100 registros de pacientes das unidades de terapia intensiva, cirúrgica e cardíaca do hospital Beth Israel, situado em Boston nos EUA, coletados entre 1994 e 1996. Como se trata de dados destinados a oferecer suporte para decisões médicas, além das gravações contínuas de dados de monitores de pacientes por até 48 horas, cada registro também conta com informações clínicas de cada paciente descritas de forma detalhada em (MOODY; MARK, 1996). Ao disponibilizar dados clínicos bem caracterizados para pesquisadores, a base de dados MIMIC possibilita que questões fisiológicas sejam formuladas e respondidas através de sistemas automatizados de suporte a decisão e, assim sendo, se caracteriza como uma fonte de dados de sensoriamento relevante para o tipo de avaliação realizada para o PSIoT-Health.

A base de dados do MIMIC consistem em vários diretórios por paciente anonimizados. Para cada paciente existem os diretórios com os seus dados fisiológicos. Cada tipo específico de sinal tem a sua periodicidade de amostragem indicada na base de dados.

Neste projeto, a operação do sensor é simulada pela varredura da base de dados MIMIC que contem as pasta de dados dos pacientes. A simulação do sensor seleciona os dados específicos a serem consumidos e os envia ao agregador do PSIoT-Health, emulando a entrega realizada por um sensor real. A cadência do envio de dados do paciente para o agregador é, para efeito de simulação da operação do sensor, sempre equivalente à taxa de leitura por parte do consumidor e reflete a captura do dado real como indicado na base de dados de amostragem.

A simulação dos sensores envia três tipos de dados (ABP, SpO2 e pulse) para o agregador. Os dados de sensores são enviados para o endereço do agregador através de uma porta e este possui um método para escutar os dados enviados no formato JSON (JavaScript Object Notation) segundo o seguinte código:

1: “tipo": “abp", "payload": “65 84 54",“time": 1024

Onde:

- Tipo é o tipo de dados enviado.

- Payload é o conteúdo do dado.

- Time informa o tempo para o envio do dado para o consumidor em milissegundos. 
O tamanho efetivo do dado coletado do sensor não é considerado para efeito da simulação de operação realizada. A simulação da operação considera que cada dado é alocado num pacote e o pacote é transmitido. Para efeito de informação, os dados efetivos das coletados são os seguintes:

- ABP: 8 Bytes ou 9 Bytes;

- SpO2: 2 Bytes ou 3 Bytes; e

- Pulse: 2 Bytes ou 3 Bytes.

Em cada inscrição realizada pelo cliente consumidor Pub/Sub, este deve indicar o tipo do dador a ser consumido, o endereço do agregador e o intervalo do tempo de recebimento desejado, conforme a linha de código abaixo:

1: “tipo": “abp", “url": "http://localhost:8088/subscribe", “time": 1024

\subsection{RESULTADOS DO TESTE DE OPERAÇÃO DO PSIOT-HEALTH}

A simulação de operação realizada com o PSIoT-Health tem os seguintes objetivos:

- Verificar a operação básica do código desenvolvido para o PSIoT-Health e a comunicação entre orquestrador e agregador; e

- Verificar se a alocação de banda é efetiva e está respeitando as prioridades alocadas para as filas com dados médicos no agregador.

Os testes foram realizados com a seguinte configuração:

- Três velocidades de enlace: $5 \mathrm{Kbps}, 10 \mathrm{Kbps}$ e $20 \mathrm{Kbps}$;

- É medida a quantidade de pacotes transmitidos por fila por minuto; e

- O teste tem uma duração de 18 minutos para cada velocidade do enlace de comunicação.

As velocidades do enlace entre o agregador e os consumidores foram escolhidas visando partir de uma situação com escassez de banda até uma situação com uma maior quantidade de banda de forma que possa ser verificado a efetividade das prioridades alocadas para as filas do agregador.

A Figura 21 apresenta a quantidade de pacotes transmitidos pelo agregador por minuto para um enlace de $5 \mathrm{Kbps}$. O resultado comprova que, em caso de escassez de banda (cenário 
de 5kbps), o algoritmo concede prioridade de transmissão de pacotes para a fila de maior prioridade, pois, mesmo com a mesma quantidade de inscrições, a fila zero transmitiu em média 1.023 pacotes por segundo e a fila um transmitiu em média 871 pacotes por segundo. Ao passo que, a fila dois, sofreu uma perda de pacotes ainda maior que a fila um, transmitindo em média 204 pacotes por segundo.

Figura 21 - Cenário com 5kbps de banda total.

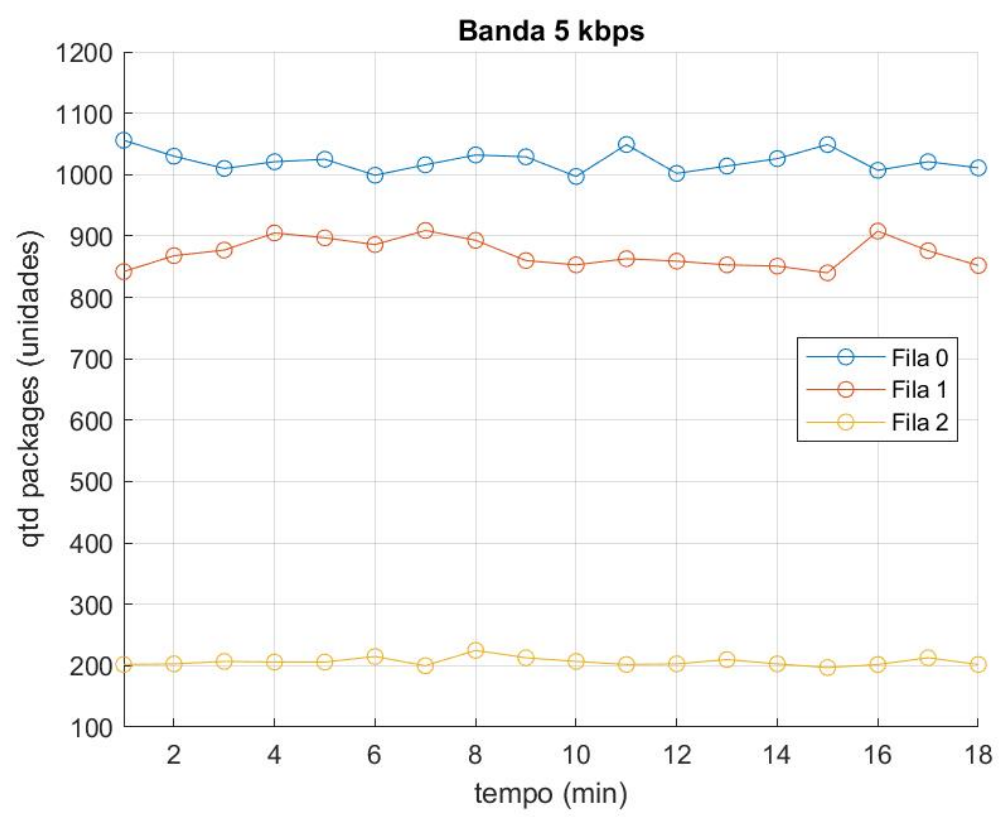

A Figura 22 apresenta a quantidade de pacotes transmitidos pelo agregador por minuto para um enlace de $10 \mathrm{Kbps}$. Neste cenário, o algoritmo conseguiu manter os fluxos das filas zero e um semelhantes, dentro do esperado, porém, a fila de menor prioridade sofreu uma grande perda de pacotes, transmitindo em média 431 pacotes por segundo. 
Figura 22 - Cenário com 10kbps de banda total.

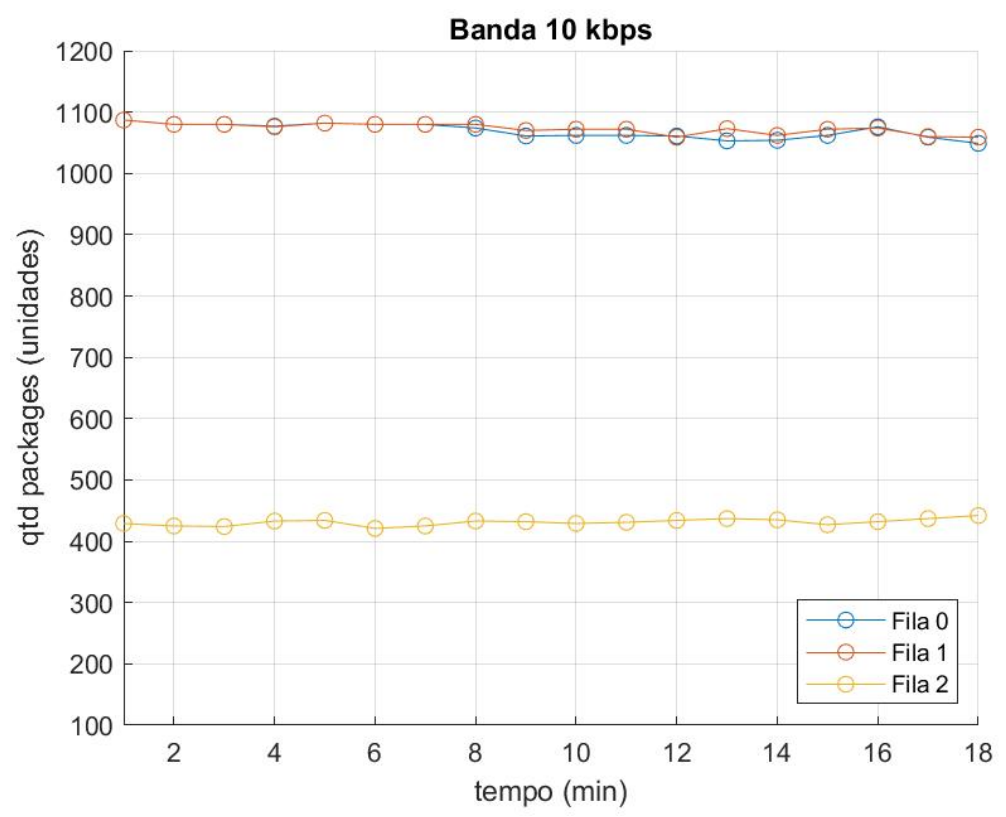

A Figura 23 apresenta a quantidade de pacotes transmitidos pelo agregador por minuto para um enlace de $20 \mathrm{Kbps}$. Neste cenário de teste, os fluxos das filas se mantiveram constante e dentro do esperado. A fila zero transmitiu em média 1072 pacotes por segundo, a fila um transmitiu em média 1073 pacotes por segundo e a fila três transmitiu em média 714 pacotes por segundo.

De maneira geral, podemos dizer em relação aos resultados dos testes realizados que o orquestrador consegue dividir a banda disponível entre as três filas conforme esperado e que mesmo quando há escassez, o mesmo respeita as prioridades determinadas fazendo com que a perda de pacotes seja mais significativas na fila de menor prioridade. 
Figura 23 - Cenário com 20kbps de banda total.

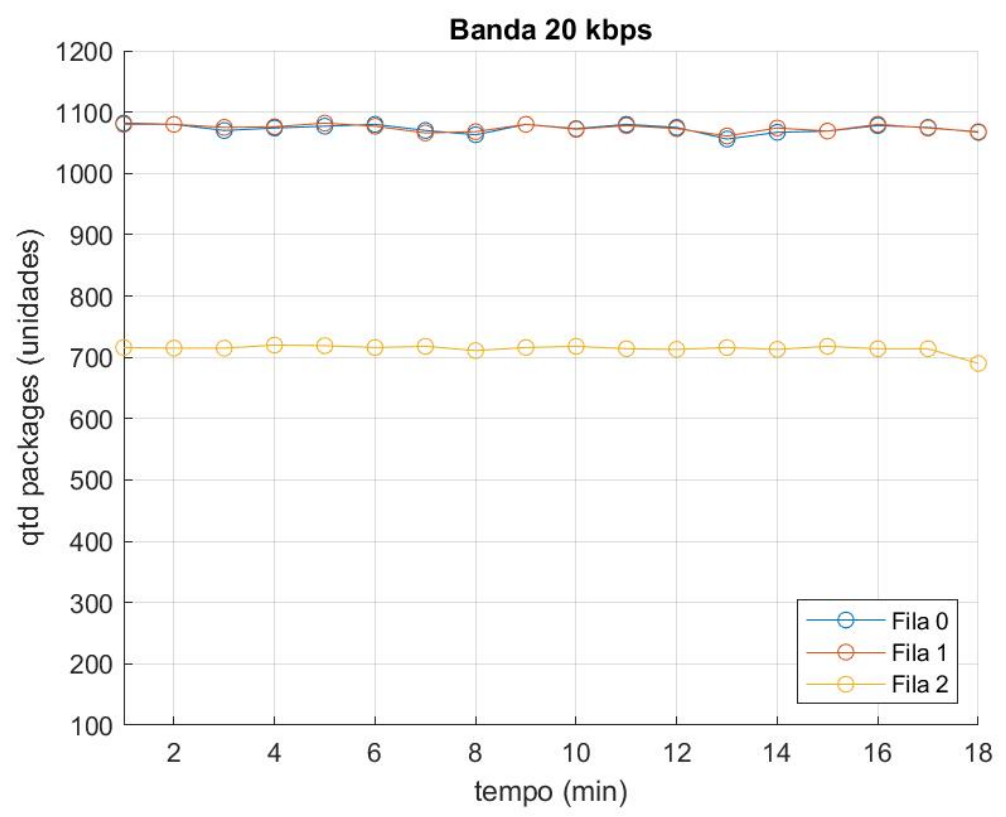




\section{CONSIDERAÇÕES FINAIS}

As contribuições do trabalho desenvolvido para a área das aplicações médicas são um agregador de dados coletados dos de pacientes que aloca a taxa de transferência necessária e envia os dados solicitados em filas de acordo com a prioridade definida pelo consumidor via inscrições no estilo Pub/Sub e um orquestrador que atua controlando as taxas de transferência de cada fila do agregador segundo as prioridades definidas para os dados.

Os aspectos positivos do PSIoT-Health em relação às aplicações que fazem uso dos dados médicos coletados incluem:

- O pré-processamento da demanda dos consumidores na borda da rede, possibilitando a alocação dinâmica da banda disponível no enlace entre o agregador e os consumidores de dados; e

- A facilidade dada ao consumidor para determinar a frequência com a qual deseja receber os dados médicos, escolha que é crucial para a aplicação médica consumindo os dados.

Um aspecto operacional que pode ser melhorado no PSIoT-Health é o controle da banda na rede, envolvendo os diversos enlaces entre o agregador e os consumidores de dados. Com relação à esta melhoria, a utilização do paradigma das redes definidas por software (Softwaredefined Networking - SDN) se apresenta como um habilitador potencial.

Os trabalhos futuros previstos com a evolução do presente trabalho incluem:

- Implementar uma técnica de aprendizado de máquina adequada para que o orquestrador realize a alocação de banda de maneira inteligente ao invés de dinâmica;

- Realizar uma bateria de testes de avaliação do desempenho do PSIoT-Health com diversos agregadores conectados em rede distribuindo os dados; e

- Realizar o processamento dos dados de modo que anomalias no estado de saúde de um paciente possam ser detectadas a partir deles. 


\section{REFERÊNCIAS}

ALBERTIN, A. L.; ALBERTIN, R. M. de M. A internet das coisas irá muito além as coisas. GV EXECUTIVO, v. 16, n. 2, p. 12-17, 2017.

ARRUDA, C. E.; MORAES, P. F.; AGOULMINE, N.; MARTINS, J. S. B. Enhanced Pub/Sub Communications for Massive IoT Traffic with SARSA Reinforcement Learning. In: Proceedings of the 3rd International Conference on Machine Learning for Networking (MLN'2020). Paris: [s.n.], 2020. p. 1-20.

ASHTON, K. et al. That internet of things thing. RFID journal, v. 22, n. 7, p. 97-114, 2009.

BEZERRA, R. M. d. S.; MARISTELA, F.; MARTINS, J. On Computational Infraestruture Requirements to Smart and Autonomic Cities Framework. In: IEEE International Smart Cities Conference - ISC2-2015. Guadalajara, Mexico: IEEE, 2015. p. 1-6.

CHEN, Y.; LI, M.; CHEN, P.; XIA, S. Survey of Cross-Technology Communication for Iot Heterogeneous Devices. IET Communications, v. 13, n. 12, p. 1709-1720, 2019. ISSN 17518628 .

CHETTRI, L.; BERA, R. A Comprehensive Survey on Internet of Things (IoT) Toward 5G Wireless Systems. IEEE Internet of Things Journal, v. 7, n. 1, p. 16-32, jan. 2020. ISSN 23722541 .

CHORBEV, I.; TRAJKOVIK, V.; GOLEVA, R. I.; GARCIA, N. M. Cloud Based Smart Living System Prototype. In: DOBRE, C.; MAVROMOUSTAKIS, C.; GARCIA, N.; GOLEVA, R.; MASTORAKIS, G. (Ed.). Ambient Assisted Living and Enhanced Living Environments. [S.1.]: Butterworth-Heinemann, 2017. p. 147-170. ISBN 978-0-12-805195-5.

COOK, D. J.; DUNCAN, G.; SPRINT, G.; FRITZ, R. L. Using smart city technology to make healthcare smarter. Proceedings of the IEEE, IEEE, v. 106, n. 4, p. 708-722, 2018.

COSTALONGA, T.; ÁVILA, L.; MUNIZ, L.; BRANDAO, A. Interface homem-máquina utilizando sensor kinect para control de um quadrotor ar. drone parrot. In: XX Congres so Brasileiro de Automática. [S.1.: s.n.], 2014.

DEMERS, A.; GEHRKE, J.; HONG, M.; RIEDEWALD, M.; WHITE, W. Towards expressive publish/subscribe systems. In: SPRINGER. International Conference on Extending Database Technology. [S.1.], 2006. p. 627-644.

DOHR, A.; MODRE-OPSRIAN, R.; DROBICS, M.; HAYN, D.; SCHREIER, G. The internet of things for ambient assisted living. In: IEEE. Information technology: new generations (ITNG), 2010 seventh international conference on. [S.1.], 2010. p. 804-809.

DOMÍNGUEZ, A. M.; ROBLES, T.; ALCARRIA, R.; CEDEÑO, E. A hot-topic based distribution and notification of events in pub/sub mobile brokers. Netw. Protoc. Algorithms, v. 5, n. 1, p. $90-110,2013$.

GOLANG.ORG. The Go Project - The Go Programming Language. 2020. Disponível em: $<$ https://golang.org/project/>. 
GOMES, G. da S.; BERGAMO, F. V. de M. Chegou a era da internet das coisas? um estudo sobre adoção de objetos inteligentes no contexto brasileiro. Revista Brasileira de Marketing, v. 17, n. 2, p. 251-263, 2018.

GROUP, I.-T. S. et al. New ITU standards define the Internet of Things and provide the blueprints for its development. [S.1.]: ITU, 2012.

GUERREIRO, S. Telemonitoring as a Core Component to Enforce Remote Biofeedback Control Systems. In: DOBRE, C.; MAVROMOUSTAKIS, C.; GARCIA, N.; GOLEVA, R.; MASTORAKIS, G. (Ed.). Ambient Assisted Living and Enhanced Living Environments. [S.1.]: Butterworth-Heinemann, 2017. p. 311-343. ISBN 978-0-12-805195-5.

HAPP, D.; KAROWSKI, N.; MENZEL, T.; HANDZISKI, V.; WOLISZ, A. Meeting iot platform requirements with open pub/sub solutions. Annals of Telecommunications, Springer, v. 72, n. 1-2, p. 41-52, 2017.

HUANG, Y.; GARCIA-MOLINA, H. Publish/subscribe in a mobile environment. Wireless Networks, Springer, v. 10, n. 6, p. 643-652, 2004.

HUSSAIN, A.; WENBI, R.; SILVA, A. L. da; NADHER, M.; MUDHISH, M. Health and emergency-care platform for the elderly and disabled people in the smart city. Journal of Systems and Software, Elsevier, v. 110, p. 253-263, 2015.

ISLAM, S. R.; KWAK, D.; KABIR, M. H.; HOSSAIN, M.; KWAK, K.-S. The internet of things for health care: a comprehensive survey. IEEE Access, IEEE, v. 3, p. 678-708, 2015.

JAMEEL, F.; HAMID, Z.; JABEEN, F.; ZEADALLY, S.; JAVED, M. A. A Survey of Deviceto-Device Communications: Research Issues and Challenges. IEEE Communications Surveys Tutorials, v. 20, n. 3, p. 2133-2168, 2018. ISSN 1553-877X.

JARIWALA, V. J.; JINWALA, D. C. Adaptablesda: Secure Data Aggregation Framework in Wireless Body Area Networks. In: DEY, N.; ASHOUR, A. S.; FONG, S. J.; BHATT, C. (Ed.). Wearable and Implantable Medical Devices. [S.1.]: Academic Press, 2020, (Advances in ubiquitous sensing applications for healthcare, v. 7). p. 79-114. ISBN 978-0-12-815369-7.

JAVED, F.; AFZAL, M. K.; SHARIF, M.; KIM, B. Internet of Things (IoT) Operating Systems Support, Networking Technologies, Applications, and Challenges: A Comparative Review. IEEE Communications Surveys Tutorials, v. 20, n. 3, p. 2062-2100, 2018. ISSN 1553-877X.

KANG, D.-H.; PARK, M.-S.; KIM, H.-S.; KIM, D.-y.; KIM, S.-H.; SON, H.-J.; LEE, S.-G. Room temperature control and fire alarm/suppression iot service using mqtt on aws. In: IEEE. 2017 International Conference on Platform Technology and Service (PlatCon). [S.1.], 2017. p. 1-5.

KOPETZ, H. Internet of things. In: Real-time systems. [S.1.]: Springer, 2011. p. 307-323.

KRAEMER, F. A.; BRATEN, A. E.; TAMKITTIKHUN, N.; PALMA, D. Fog computing in healthcare-a review and discussion. IEEE Access, IEEE, v. 5, p. 9206-9222, 2017.

LACERDA, F.; LIMA-MARQUES, M. Da necessidade de princípios de arquitetura da informação para a internet das coisas. Perspectivas em Ciência da Informação, SciELO Brasil, v. 20, n. 2, p. 158-171, 2015. 
LEE, S. K.; BAE, M.; KIM, H. Future of iot networks: A survey. Applied Sciences, Multidisciplinary Digital Publishing Institute, v. 7, n. 10, p. 1072, 2017.

LI, S.; XU, L. D.; ZHAO, S. The internet of things: a survey. Information Systems Frontiers, Springer, v. 17, n. 2, p. 243-259, 2015.

MADAKAM, S.; LAKE, V.; LAKE, V.; LAKE, V. et al. Internet of things (iot): A literature review. Journal of Computer and Communications, Scientific Research Publishing, v. 3, n. 05, p. 164, 2015.

MAHMUD, R.; KOTAGIRI, R.; BUYYA, R. Fog computing: A taxonomy, survey and future directions. In: Internet of everything. [S.1.]: Springer, 2018. p. 103-130.

MAIA, A. M. Um mercanismo para escalonamento de pacotes no uplink da rede lte no contexto da comunicação máquina-a-máquina. 2013.

MARTINS, G. J. D. U.; GONÇALVES, R. F. Blockchain na revolução da manufatura baseada em transação máquina-a-máquina. 2017.

MARTINS, J. S. B. Towards Smart City Innovation Under the Perspective of Software-Defined Networking, Artificial Intelligence and Big Data. Revista de Tecnologia da Informação e Comunicação, v. 8, n. 2, p. 1-7, out. 2018. ISSN 2237-5104.

MASEK, P.; HOSEK, J.; ZEMAN, K.; STUSEK, M.; KOVAC, D.; CIKA, P.; MASEK, J.; ANDREEV, S.; KRÖPFL, F. Implementation of true iot vision: survey on enabling protocols and hands-on experience. International Journal of Distributed Sensor Networks, SAGE Publications Sage UK: London, England, v. 12, n. 4, p. 8160282, 2016.

MOODY, G. B.; MARK, R. G. A database to support development and evaluation of intelligent intensive care monitoring. In: IEEE. Computers in Cardiology 1996. [S.1.], 1996. p. 657-660.

MORAES, P. F. A Publish/Subscribe QoS-Aware Framework for Massive IoT Traffic Orchestration. Tese (Dissertation MSc) — Universidade Salvador - UNIFACS, 2018.

MORAES, P. F.; MARTINS, J. S. A pub/sub sdn-integrated framework for iot traffic orchestration. In: Proceedings of the 3rd International Conference on Future Networks and Distributed Systems. [S.1.: s.n.], 2019. p. 1-9.

MORAES, P. F.; REALE, R. F.; MARTINS, J. S. B. A Publish/Subscribe QoS-aware Framework for Massive IoT Traffic Orchestration. In: Proceedings of the 6th International Workshop on ADVANCEs in ICT Infrastructures and Services (ADVANCE). Santiago, Chile: Université Paris-Saclay Évry, 2018. p. 1-14.

MSHALI, H.; LEMLOUMA, T.; MOLONEY, M.; MAGONI, D. A Survey on Health Monitoring Systems for Health Smart Homes. International Journal of Industrial Ergonomics, v. 66, p. 26-56, jul. 2018. ISSN 0169-8141.

MUKHERJEE, M.; SHU, L.; WANG, D. Survey of Fog Computing: Fundamental, Network Applications, and Research Challenges. IEEE Communications Surveys Tutorials, v. 20, n. 3, p. 1826-1857, 2018. ISSN 1553-877X.

NETO, J. R. T.; FILHO, P. G.; MANO, L. Y.; UEYAMA, J. Inca: Um sistema healthcare flexível baseado no paradigma fog computing e publish/subscribe. In: SBC. Anais do I Workshop de Computação Urbana. [S.1.], 2017. 
NOUR, B.; SHARIF, K.; LI, F.; YANG, S.; MOUNGLA, H.; WANG, Y. ICN PublisherSubscriber Models: Challenges and Group-based Communication. IEEE Network, v. 33, n. 6, p. 156-163, nov. 2019. ISSN 1558-156X. Conference Name: IEEE Network.

OTTO, C. A.; JOVANOV, E.; MILENKOVIC, A. A WBAN-based System for Health Monitoring at Home. In: 20063 rd IEEE/EMBS International Summer School on Medical Devices and Biosensors. Cambridge, MA, USA: IEEE, 2006. p. 20-23. ISBN 978-0-7803-9786-6 9780-7803-9787-3.

PACHECO, F. B.; KLEIN, A. Z.; RIGHI, R. da R. Modelos de negócio para produtos e serviços baseados em internet das coisas: uma revisão da literatura e oportunidades de pesquisas futuras. REGE-Revista de Gestão, Elsevier, v. 23, n. 1, p. 41-51, 2016.

PEIZHONG, Y.; IWAYEMI, A.; ZHOU, C. Developing ZigBee Deployment Guideline Under Wifi Interference for Smart Grid Applications. IEEE Transactions on Smart Grid, v. 2, n. 1, p. 110-120, 2011.

PRAMANIK, P. K. D.; NAYYAR, A.; PAREEK, G. WBAN: Driving e-healthcare Beyond Telemedicine to Remote Health Monitoring: Architecture and Protocols. In: JUDE, H. D.; BALAS, V. E. (Ed.). Telemedicine Technologies. [S.1.]: Academic Press, 2019. p. 89-119. ISBN 978-012-816948-3.

QUINCOZES, S.; EMILIO, T.; KAZIENKO, J. Mqtt protocol: Fundamentals, tools and future directions. IEEE Latin America Transactions, IEEE, v. 17, n. 09, p. 1439-1448, 2019.

RAHMANI, A. M.; GIA, T. N.; NEGASH, B.; ANZANPOUR, A.; AZIMI, I.; JIANG, M.; LILJEBERG, P. Exploiting smart e-health gateways at the edge of healthcare internet-of-things: A fog computing approach. Future Generation Computer Systems, Elsevier, v. 78, p. 641-658, 2018 .

REYNA, A.; MARTÍN, C.; CHEN, J.; SOLER, E.; DÍAZ, M. On blockchain and its integration with iot. challenges and opportunities. Future generation computer systems, Elsevier, v. 88, p. 173-190, 2018.

SANTOS, B. P.; SILVA, L.; CELES, C.; BORGES, J. B.; NETO, B. S. P.; VIEIRA, M. A. M.; VIEIRA, L. F. M.; GOUSSEVSKAIA, O. N.; LOUREIRO, A. Internet das coisas: da teoriaa prática. Minicursos SBRC-Simpósio Brasileiro de Redes de Computadores e Sistemas Distribuidos, 2016 .

SEBESTYEN, G.; HANGAN, A.; ONIGA, S.; GÁL, Z. ehealth solutions in the context of internet of things. In: IEEE. Automation, Quality and Testing, Robotics, 2014 IEEE International Conference on. [S.1.], 2014. p. 1-6.

SILVA, K. C. N. d. Monitoramento da saúde humana através de sensores: análise de incertezas contextuais através da teoria da evidência de Dempster-Shafer. Tese (Doutorado) — Universidade de São Paulo, 2013.

SOLANAS, A.; PATSAKIS, C.; CONTI, M.; VLACHOS, I. S.; RAMOS, V.; FALCONE, F.; POSTOLACHE, O.; PÉREZ-MARTÍNEZ, P. A.; PIETRO, R. D.; PERREA, D. N. et al. Smart health: a context-aware health paradigm within smart cities. IEEE Communications Magazine, IEEE, v. 52, n. 8, p. 74-81, 2014. 
STRAPAZZON, C. L. Convergência tecnológica nas políticas urbanas: pequenas e médias cidades inteligentes. Revista Jurídica, v. 22, n. 6, p. 89-108, 2009.

TAN, L.; WANG, N. Future internet: The internet of things. In: IEEE. $20103 \mathrm{rd}$ international conference on advanced computer theory and engineering (ICACTE). [S.1.], 2010. v. 5, p. V5376.

THAMAY, F.; MORAIS, M. E. d. Monitoramento de crianças e idosos utilizando uma WBAN. Revista de Saúde Digital e Tecnologias Educacionais, v. 2, n. 4, p. 68-82, jun. 2018. ISSN 2525-9563.

WU, H.; SUN, D.; PENG, L.; YAO, Y.; WU, J.; SHENG, Q. Z.; YAN, Y. Dynamic Edge Access System in IoT Environment. IEEE Internet of Things Journal, v. 7, n. 4, p. 2509-2520, abr. 2020. ISSN 2327-4662. Conference Name: IEEE Internet of Things Journal.

WU, J.; DONG, M.; OTA, K.; LI, J.; YANG, W.; WANG, M. Fog-Computing-Enabled Cognitive Network Function Virtualization for an Information-Centric Future Internet. IEEE Communications Magazine, v. 57, n. 7, p. 48-54, jul. 2019. ISSN 0163-6804.

XIA, F.; YANG, L. T.; WANG, L.; VINEL, A. Internet of things. International journal of communication systems, v. 25, n. 9, p. 1101, 2012.

XU, J.; XU, L. Sensor System and Health Monitoring. In: XU, J.; XU, L. (Ed.). Integrated System Health Management. Academic Press, 2017. p. 55-99. ISBN 978-0-12-812207-5. Disponível em: <http://www.sciencedirect.com/science/article/pii/B978012812207500002X>.

YÁN, L.; SCHAFFER, P. Position-based aggregator node election in wireless sensor networks. International Journal of Distributed Sensor Networks, SAGE Publications Sage UK: London, England, v. 6, n. 1, p. 679205, 2010.

YANNUZZI, M.; MILITO, R.; SERRAL-GRACIÀ, R.; MONTERO, D.; NEMIROVSKY, M. Key ingredients in an iot recipe: Fog computing, cloud computing, and more fog computing. In: IEEE. 2014 IEEE 19th International Workshop on Computer Aided Modeling and Design of Communication Links and Networks (CAMAD). [S.1.], 2014. p. 325-329.

ZHANG, Y.; XIONG, Z.; NIYATO, D.; WANG, P.; HAN, Z. Information Trading in Internet of Things for Smart Cities: A Market-Oriented Analysis. IEEE Network, v. 34, n. 1, p. 122-129, jan. 2020. ISSN 1558-156X.

ZHONG, C.; ZHU, Z.; HUANG, R. Study on the IOT Architecture and Gateway Technology. In: . [S.1.: s.n.], 2015. p. 196-199. 